\title{
Continuing Results for Effervescent Aerosol Salt Water Spray Nozzles Intended for Marine Cloud Brightening
}

\author{
Jack Foster 1,2, Gary Cooper ${ }^{1,2}$, Lee Galbrath ${ }^{1,2}$, Sudhanshu Jain ${ }^{1,2}$, Robert Ormond ${ }^{1,2}$, \\ Armand Neukermans ${ }^{1,2}$ \\ ${ }^{1}$ Climate Crises Volunteers, Sunnyvale, CA, USA \\ ${ }^{2}$ Presently volunteering at Parc, Xeros Company, Palo Alto, CA, USA \\ Email: jackdfoster@hotmail.com
}

How to cite this paper: Foster, J., Cooper, G., Galbrath, L., Jain, S., Ormond, R. and Neukermans, A. (2020) Continuing Results for Effervescent Aerosol Salt Water Spray Nozzles Intended for Marine Cloud Brightening. International Journal of Geosciences, 11, 563-589.

https://doi.org/10.4236/ijg.2020.119030

Received: August 19, 2020

Accepted: September 27, 2020

Published: September 30, 2020

Copyright $\odot 2020$ by author(s) and Scientific Research Publishing Inc. This work is licensed under the Creative Commons Attribution International License (CC BY 4.0).

http://creativecommons.org/licenses/by/4.0/

(c) (i) Open Access

\begin{abstract}
Marine Cloud Brightening (MCB) by effervescent spray atomization of mixed sea water brine with air is a candidate for solar radiation management to compensate for global warming. We discovered that the flow from mixing tee nozzle described earlier had occasional unstable slug flow. A new design that adding rotational swirl to the salt brine as it is mixed into the air stabilized the nozzle flow and no longer showed slug flow in spray pictures. Flow equations were developed for the relatively low speed of sound of a choked flow mixed brine and air nozzle. Experimental mixed flow measurements with $300 \mathrm{~b}$ pressure and a $200 \mu \mathrm{m}$ diameter nozzle and calculations using perfect gas, and isotropic processes equations compared well with the chocked flow equations. Analysis in EXCEL of particle sizers measurements from both a scanning mobility particle sizer (SMPS) and an aerodynamic particle sizer (APS) showed production of many nanometer sized particles estimated as usable for MCB. A small number of micron sized particles were also always present but with about $90 \%$ of the sprayed mass. This is a first report with good data over the complete size range. The micron sized particles measured were similar to the measurements of earlier reports which reported no nanometer sized particles. We hypothesize that many nano-particles are always produced by liquid-air effervescent sprays, but earlier, were not observed because SMPS instruments were not available. The presence of the large mass percentage of large particles in the spray may cause problems by evaporative cooling preventing the rise of the MCB particles. We suggest future systems design with an impactor filter to remove the large particles. Calculations combining increased brine concentration, lower pressure, and larger nozzle area showed that significant reductions in required power and number of
\end{abstract}


nozzles could be realized. An EXCEL model is developed to calculate flow from experimental analysis equations and compare with mixed choked flow equations. Solving with the model predicted the power required and the number of nozzles required to produce $10^{15}$ particles/s. The model showed that increasing brine concentration strongly lowered total power. Lowering pressure decreased power and increased number of nozzles. Increasing nozzle area lowered the number of nozzles. This model predicted that, at $300 \mathrm{~b}$ pressure and $200 \mu \mathrm{m}$ diameter nozzle as the experiment but using an increased brine concentration of 0.1 instead of 0.032 would require only 115 nozzles instead of 358 and power of $146 \mathrm{kw}$ instead of $493 \mathrm{kw}$. Combining increased brine concentration, lower pressure, and larger nozzle area, the model predicted that with a $1 \mathrm{~mm}$ diameter nozzle at $30 \mathrm{~b}$ pressure and salt concentration of 0.2 , the nozzle count and power required would drop to only 24 nozzles and power of $28 \mathrm{kw}$. Whether extending the model to these conditions is valid is not known but suggests further development should be investigated. Filtering out and reusing the $90 \%$ or greater large particles mass sprayed combined with the lower power advantage of higher brine concentration is suggested for future systems.

\section{Keywords}

Marine Cloud Brightening, Global Warming, Effervescent Spray Nozzles, Salt Nano-Particles

\section{Introduction}

Latham [1] [2] first proposed the idea to seed marine stratocumulus clouds with sea water brine to increase the cloud albedo (Marine Cloud Brightening, MCB). Our volunteer group of retired scientists and engineers in Silicon Valley, California has been studying various possible techniques for MCB with brine aerosols for some time [3] [4] [5] [6].

The fact that a mixture of air and liquid has a speed of sound less than either the air or the liquid was shown by Wood [7]. Others have noted the importance of this for production of smaller particles in the pressure jump at the choked flow nozzle exit in effervescent spray [8] [9]. Our calculation of flow in effervescent nozzle spray has been developed from the lowered speed of sound, perfect gas relations and isentropic processes. The theory predictions for high pressure $300 \mathrm{~b}$ effervescent spray nozzle matched experimental data very well.

A new nozzle was designed with rotational swirl flow of brine into the air. Improved mixing and centrifugal force of the brine to the inside of the nozzle resulted in better particle production. Pictures indicated no slug flow and a smooth spray [10].

To simplify the text, pressure units in bars will be used in the following discussions $\left(1 \mathrm{~b}=10^{5}\right.$ Pascal). Earlier studies [6] suggested that high pressure was required to produce small particles. Many of our experiments were at high pres- 
sure, but some experiments at lower pressures indicated high pressure was not required. Data from an experiment at $300 \mathrm{~b}$ pressure was chosen for this summary.

Earlier studies [6] [11] were performed with measuring apparatus which could not adequately detect small particles. For this study, appropriate measurement apparatus, were borrowed for the experiments, a scanning mobility particle sizer, SMPS [12] [13] [14] for measuring particles with diameters from $10 \mathrm{~nm}$ to 700 $\mathrm{nm}$ diameters and an aerodynamic particle sizer spectrometer, APS [15] for measuring particle diameters from $700 \mathrm{~nm}$ to $13 \mu \mathrm{m}$. Later our group purchased both instruments on the surplus market. This is the first report with good data over the complete size range. This allowed calculation of spray characteristics and predictions of parameter effects not possible before.

Effervescent sprays using air and a liquid have been utilized for a long time. Sovani [11] et al., reviewed a number of investigations. None of these reported small particles in the MCB range. Our measurements with SMPS showed a considerable number of particles were produced in the MCB range. The APS showed that a small number of large particles were produced that contained about $90 \%$ of the sprayed mass. These large particle size distributions were consistent with past observations. It is suspected that past researchers lacked instruments that could detect small sized particles. The presence of the large mass percentage of large particles in the spray may cause problems by evaporative cooling preventing the rise of the MCB particles.

During an experiment, three successive scans with the SMPS and the APS particle sizers of the particle numbers $/ \mathrm{cm}^{3}$ and mass $/ \mathrm{cm}^{3}$ versus diameter were taken of the sprayed particles over time. The data from the particle sizers was analyzed in EXCEL to calculate various particle and mass sums and ratios

The three scans were used to analyze room air particle size changes over approximately $15 \mathrm{~min}$ post spraying. The salt particles required for MCB which were predicted to be in range of $35 \mathrm{~nm}$ to $495 \mathrm{~nm}$ diameters. Prediction of a different range should not affect the results significantly. The EXCEL analysis included calculating ratios of total particles to particles estimated as usable for $\mathrm{MCB}$, too small to use, and too large to use. The ratio of the particles that were too small for MCB was observed to decrease over the sampling time. The ratio of those usable for $\mathrm{MCB}$ conversely increased over time. We hypothesize that some particles that were too small coagulated and increase the number of usable sized particles. The mass ratio for those too large remained at approximately $90 \%$. Power and number of nozzles required for MCB were for estimated production of $10^{15}$ particles/s but if a larger required number of particles is estimated the required power and nozzles will change by the ratio of the two estimates. The number of nozzles required to produce $10^{15}$ particles/s was calculated without considering coagulation.

Combining the equations from the experimental mixed flow, and the particle sizer analysis, an equation, $C_{b} \rho_{b} F_{b 15}=37.9 \mathrm{kgl} / \mathrm{m}^{3}$ was used to develop an EXCEL model to calculate flow from the experimental flow equations and compare with 
theoretical mixed choked flow equations. $C_{b}$, in $\mathrm{kg} / \mathrm{kg}$ solution, is brine concentration, $\rho_{b}$, in $\mathrm{kg} / \mathrm{m}^{3}$, is brine density and $F_{b 15}$, in $1 / \mathrm{s}$, is the brine flow required for production of $10^{15}$ particles/s. Solving predicted the power required and the number of nozzles required for $10^{15}$ particles/s for variation in brine concentration, pressure, and nozzle diameter. The model showed that increasing brine concentration strongly lowered the power. Lowering pressure decreased the power and increased the number of nozzles. Increasing nozzle area lowered the number of nozzles. Calculations combining increased brine concentration, lower pressure, and larger nozzle area showed that significant reductions in required power and number of nozzles could both be realized.

Filtering out and reusing the $90 \%$ or greater large particles mass sprayed combined with the lower power advantage of higher brine concentration is suggested for future systems.

Following, we present a theory of an effervescent spray nozzle, design of an improved nozzle, and description of experimental apparatus. Experimental flow results using the apparatus are compared with the theory and particle measurements results. Particle size variation with time after spraying is presented. A model of required power and number of nozzles is developed for variations in brine concentration, pressure, and nozzle area.

\section{Effervescent Spray Nozzle}

A theory will be developed of effervescent spray followed by description of a nozzle design and apparatus for testing.

\subsection{Theory of Nozzle Air and Brine Effervescent Spray}

Spray through a converging nozzle develops choked flow at a critical exit pressure when the exit velocity attains the speed of sound. After that, the exit pressure will not increase when the source stagnation pressure is increased but will produce a pressure jump with shocks at the nozzle exit which breaks the spray up into small particles.

The speed of sound, a is given by,

$$
a=\sqrt{\frac{E}{\rho}} .
$$

where $E$ is the bulk modulus and $\rho$ is the density. The speed of sound can be calculated for a homogeneous mixture of air and brine with a mean density $\rho_{m i x}$ and mean bulk modulus $E_{m i x}$ [7]. For $\rho_{a} E_{a}$ and $\rho_{b} E_{b}$, the density and bulk elasticity of the air and the brine components at the nozzle exit and $x$ the proportion of air by volume and $(1-x)$ the proportion of brine by volume at the nozzle exit, the density is,

$$
\rho_{\text {mix }}=x \rho_{a}+(1-x) \rho_{b} .
$$

The compressibility is,

$$
\frac{1}{E_{\text {mix }}}=\frac{x}{E_{a}}+\frac{(1-x)}{E_{b}} .
$$


The speed of sound is,

$$
a_{\text {mix }}=\sqrt{\frac{E_{\text {mix }}}{\rho_{\text {mix }}}}=\sqrt{\frac{E_{a} E_{b}}{\left(x E_{b}+(1-x) E_{a}\right)\left(x \rho_{a}+(1-x) \rho_{b}\right)}} .
$$

Rearranging the equations with $a_{a}$ and $a_{b}$ substituted for the speed of sound of air and brine [8] gives,

$$
a_{\text {mix }}=\sqrt{\frac{x}{\frac{x}{a_{a}^{2}}\left[1+(1-x)\left(\frac{\rho_{b}}{\rho_{a}}-1\right)\right]+\frac{(1-x)}{a_{b}^{2}}\left[1+x\left(\frac{\rho_{a}}{\rho_{b}}-1\right)\right]}} .
$$

For an ideal gas isentropic process, the critical pressure [16] for reaching the speed of sound at the nozzle exit is,

$$
P_{c}=\left(\frac{2}{k+1}\right)^{\frac{k}{k-1}} P_{o}=0.528 P_{o} .
$$

where $P_{o}$ is the stagnation pressure, $P_{c}$ is the critical exit pressure of the nozzle and $k$ is the specific heat ratio. The value of $k$ for air or nitrogen is 1.4, and the critical pressure for air-brine mixtures is the same for air or nitrogen gasses. For spray into the atmosphere at $1.0133 \mathrm{~b}$ the minimum stagnation pressure to achieve sound speed is $1.0133 / 0.528=1.92 \mathrm{~b}$.

Stagnation pressures above those required for the critical pressure ratio will appear as a pressure jump, $\Delta P$, at the output of the nozzle.

$$
\Delta P=P_{o}-P_{c}=0.472 P_{o} .
$$

The density of air, $\rho_{a o}$ to use in Equation (1), is that at the critical pressure, $P_{c}$.

$$
\rho_{a c}=\rho_{a t m} \frac{P_{c}}{P_{s t m}},
$$

where $\rho_{\text {atm }}=1.205 \mathrm{~kg} / \mathrm{m}^{3}$ and $P_{\text {atm }}=1.0133 \mathrm{~b}$ and the density of incompressible brine to use in Equation (1) for concentration $C_{b}=0.032$, is $\rho_{b}=1020 \mathrm{~kg} / \mathrm{m}^{3}$.

For nozzle exit area, $A_{n o z}$ the mixed gas and brine flow volume, $S_{\operatorname{mix}}$ at the exit of the nozzle is,

$$
S_{\text {mix }}=a_{\text {mix }} A_{\text {noz }} .
$$

The speed of sound at various stagnation pressures and air and brine mix ratios, is shown in Figure 1, with the brine speed of sound about $1500 \mathrm{~m} / \mathrm{s}$ and air about $346 \mathrm{~m} / \mathrm{s}$.

\subsection{Effervescent Spray Nozzle Design}

The spray nozzle described earlier [6], which used a Valco HPLC tee with salt brine input on the bottom, air input on the left and a sapphire $200 \mu \mathrm{m}$ diameter nozzle on the right is shown in Figure 2. Photographs showed that this nozzle was varying between spray and slug flow during operation. These spray modes for an effervescent nozzle are described by Sovani et al. [11]. Spray mode flow with mixed gas and liquid produces small particles. Slug flow is when gas and liquid separates into slugs of each along the flow. A sequence of photos captured this. Figure 2 shows the flow primarily in the spray mode and Figure 3 shows the flow intermittently in the slug mode. 


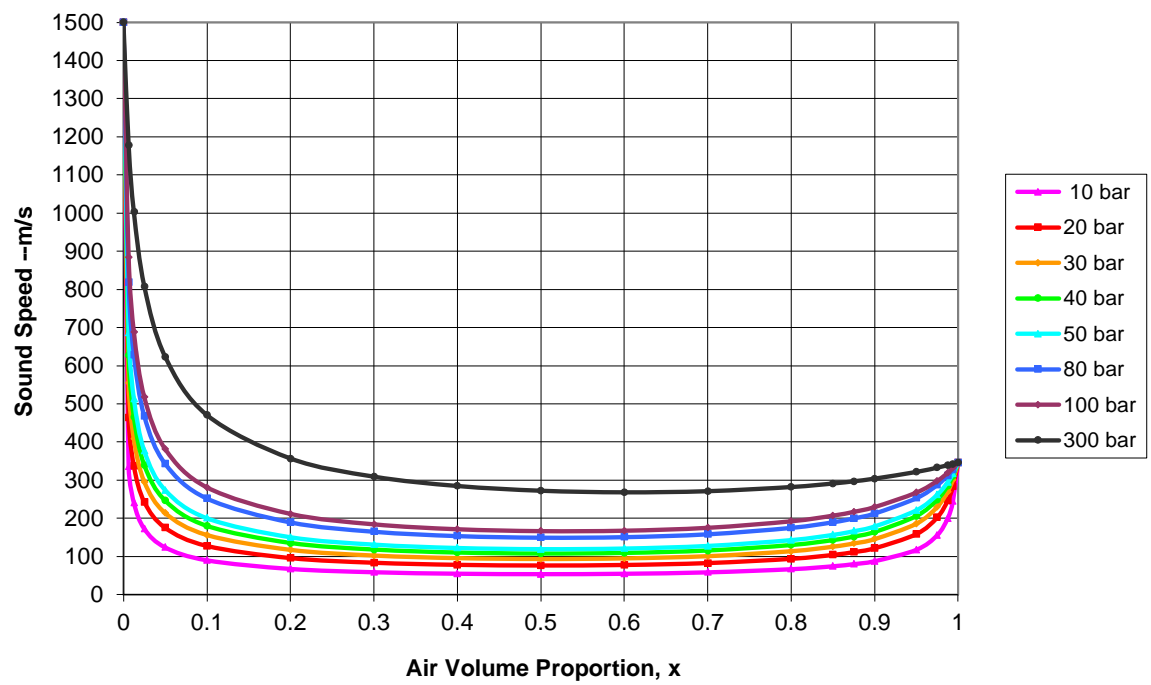

Figure 1. Sound speed for air and brine effervescent nozzle.

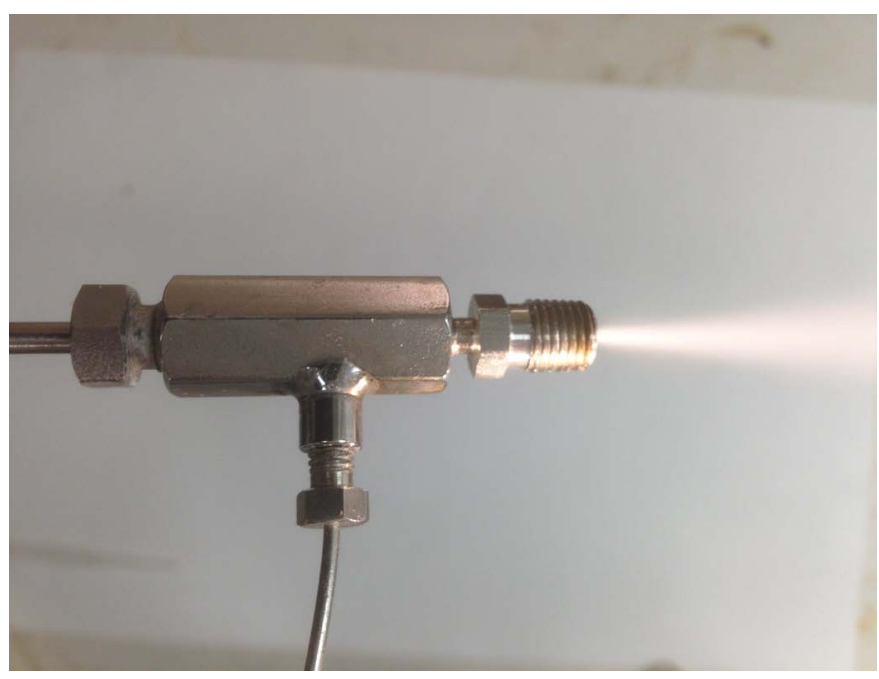

Figure 2. Mixed flow out of HPLC tee and nozzle.

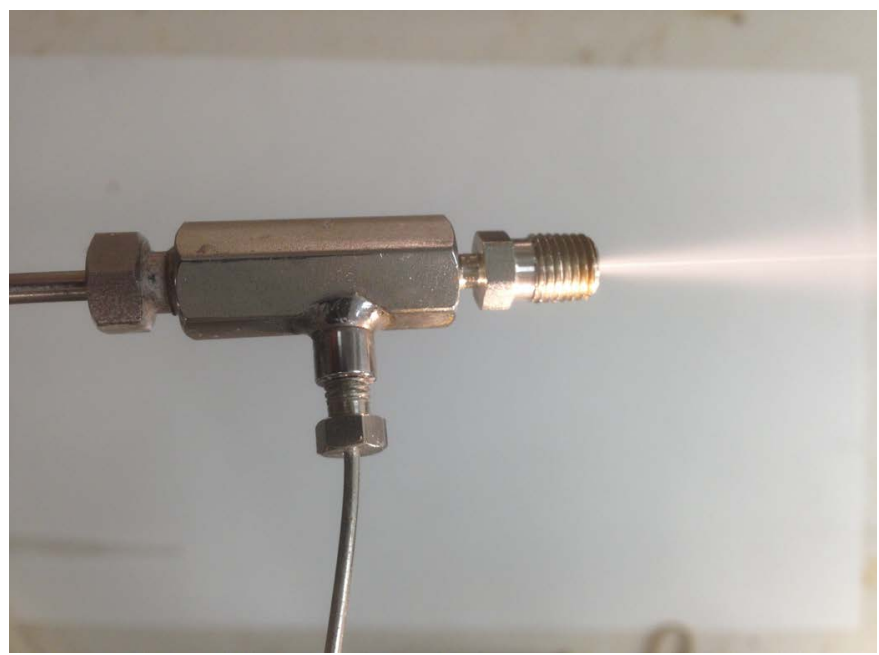

Figure 3. Slug flow out of HPLC tee and nozzle. 
Exactly how liquid drops are produced in an effervescent nozzle is questionable. One hypothesis is that an annulus forms when surface tension holds the liquid to the inside surface of the nozzle, which then exits as a thin annulus which explodes producing small particles in the exit pressure drop, $\Delta P$ outside the nozzle. Another hypothesis is that bubbles and drops in the exit pressure drop explode whenever their size is larger than those stable under surface tension with their internal pressure at the nozzle exit [8] [9]. Both mechanisms probably contribute.

To address both of these hypotheses, a nozzle was designed with a mixing region having centrifugal swirl flow that mix the gas and liquid more homogeneously reducing bubbles and drop sizes. The added centrifugal force may help hold the liquid annulus to the inside nozzle surface. Figure 4 shows a sketch of this nozzle. Salt water brine comes in from the bottom and air comes in at the left end. Spray comes out at the right.

Figure 5 shows the flows in cross section. Four tangential cutouts in a tube with internal air flow inject the brine tangentially into a mixing region producing a swirl in the flow. The mixing region leads to a conical entrance in a sapphire nozzle providing a speed up of the swirl flow into the nozzle. This assembly provided a good spray and no evidence of slug flow [10]. This design allowed stable operation with liquid pressure only slightly above the air pressure minimizing impedance required on the liquid inlets. Sapphire nozzle orifices varying in diameter from 100 to $300 \mu \mathrm{m}$ were available to mount on the swirl assembly. Operating pressures typically ranged from 30 to 300 bar.

With brine and air at appropriate pressure, the spray jet can be observed to explosively diverge from the orifice into a cone projecting forward. This swirl nozzle in operation is shown in Figure 6 [10].

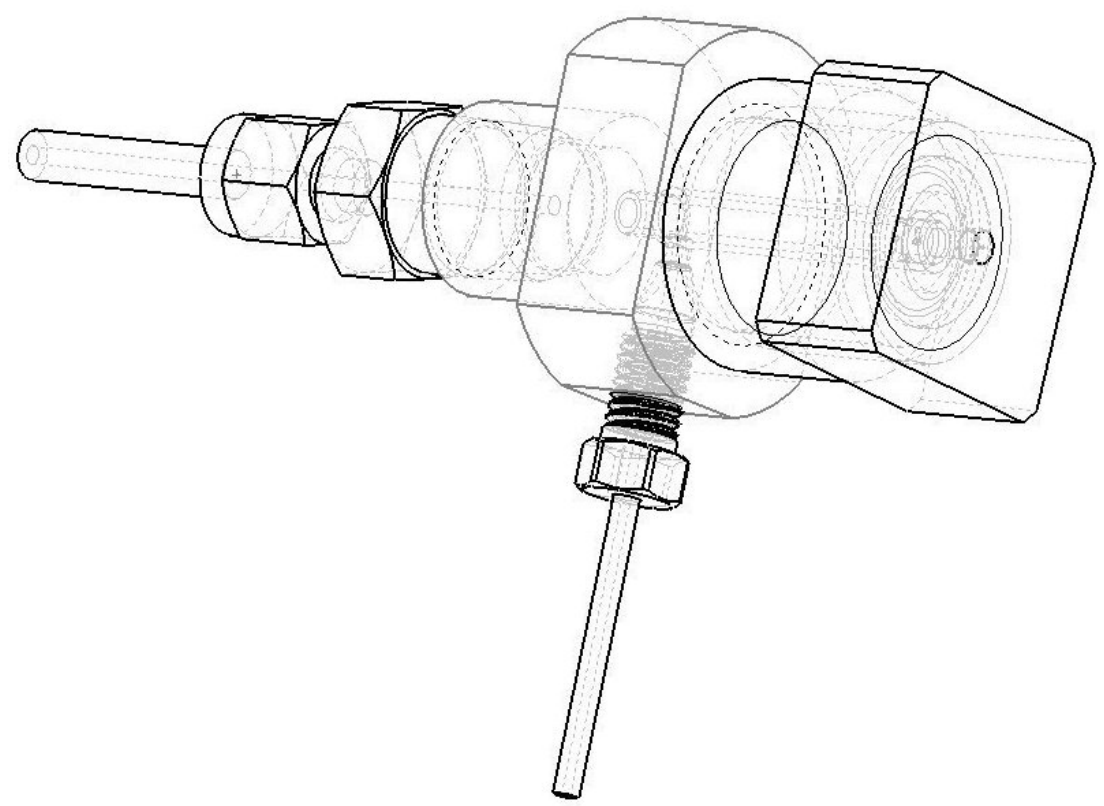

Figure 4. Sketch of nozzle with swirl flow of salt water into air. 


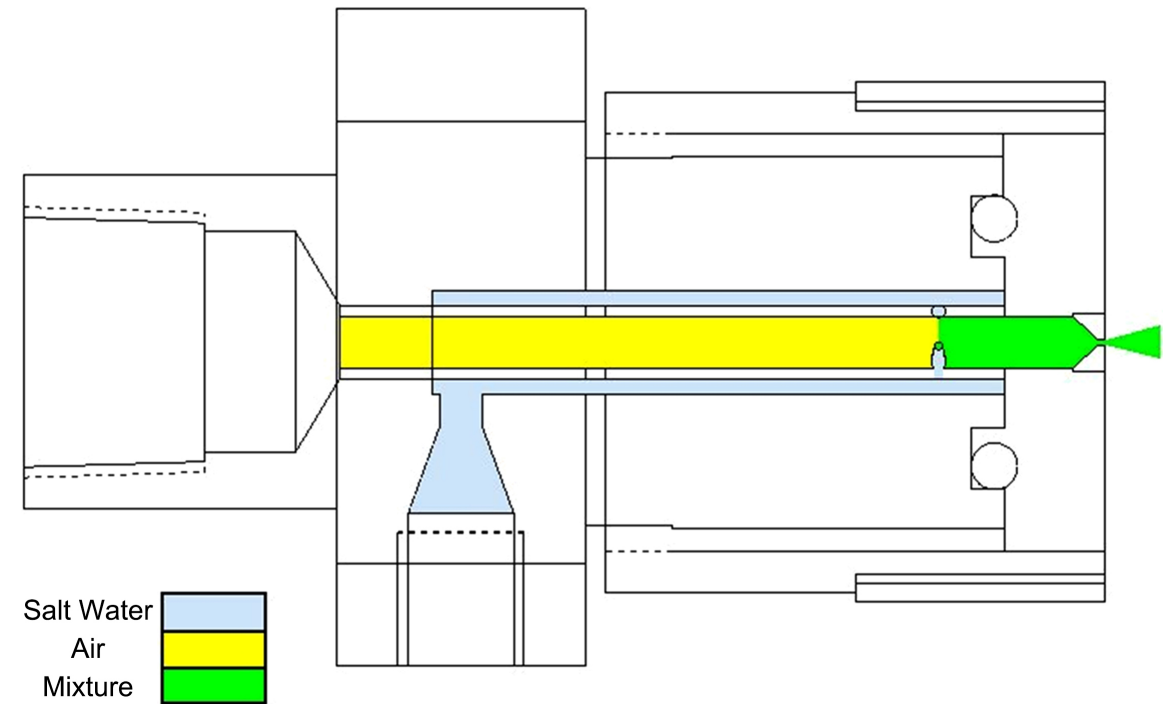

Figure 5. Cross section view of flow of salt water tangential injection into air in mixing region of nozzle.

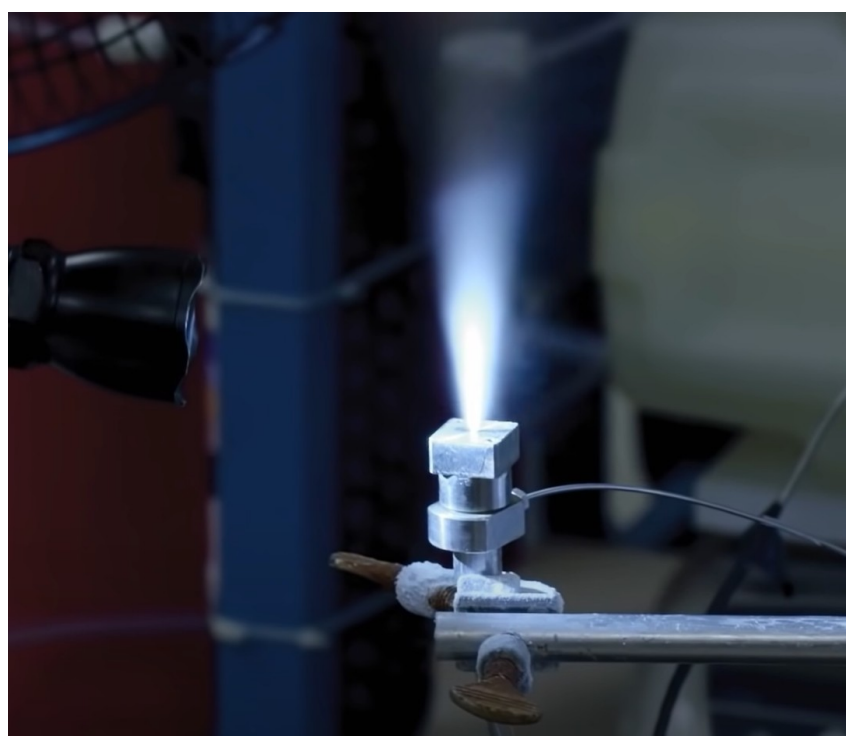

Figure 6. Swirl nozzle in operation [10].

\subsection{Description of Experimental Apparatus}

A schematic of the apparatus for effervescent spray of salt water brine with improvements to that described in [6] is shown in Figure 7.

It comprises a pump with two liquid reservoirs; one containing brine and the other containing distilled water for flushing and cleaning, both connect alternately with a two-way valve to the pump inlet. A Haskel Model SF-60 pump uses compressed air (not shown) on a large piston to drive a small piston that pumps the liquid, giving a pressure boost of 69:1. The pump's fluid cylinder has a capacity of $11.3 \mathrm{ml}$. Given the known stroke volume, the time interval between strokes provides a reliable measurement of the brine flow rate. Following the pump is a pressure gauge, an on-off valve, a filter and a flow accumulator to re- 
duce fluctuations from the pump pulses. The fluid flows through a capillary tubing flow impedance into the swirl flow spray nozzle assembly. A gas supply connects to the other input of the swirl flow assembly and consists of a compressed gas cylinder, a pressure regulator, an on-off valve, a filter and a check valve.

The gas flow is measured by attaching tubing to the nozzle outlet, directing the combined brine and air flow from it through a tube into the bottom of a large bottle to gravitationally separate out the gas from the brine and measuring the gas flow from the top of the bottle with a TSI 4043 flow meter [17].

The nozzle output was sprayed into a large $7.3 \times 7.9 \times 2.7 \mathrm{~m}$ room with a total volume of $156 \mathrm{~m}^{3}$, where the brine particles evaporated leaving $\mathrm{NaCl}$ crystals. The relative humidity of the room was reduced by a dehumidifier to below $45 \%$ RH before each experiment. Below 45\% RH salt brine particles will efflorescence to a dry minimum size salt crystal [18]. HEPA filters are run in the room before the experiment until the background particle count was low measuring with SMPS and APS particle sizing instruments. For each experiment, the nozzle was sprayed for only approximately 45 seconds while a fan continually mixes and circulates spray with the room air. The resulting room aerosol content was analyzed with the SMPS and APS particle sizing instruments (described below) over approximately 15 minutes per run.

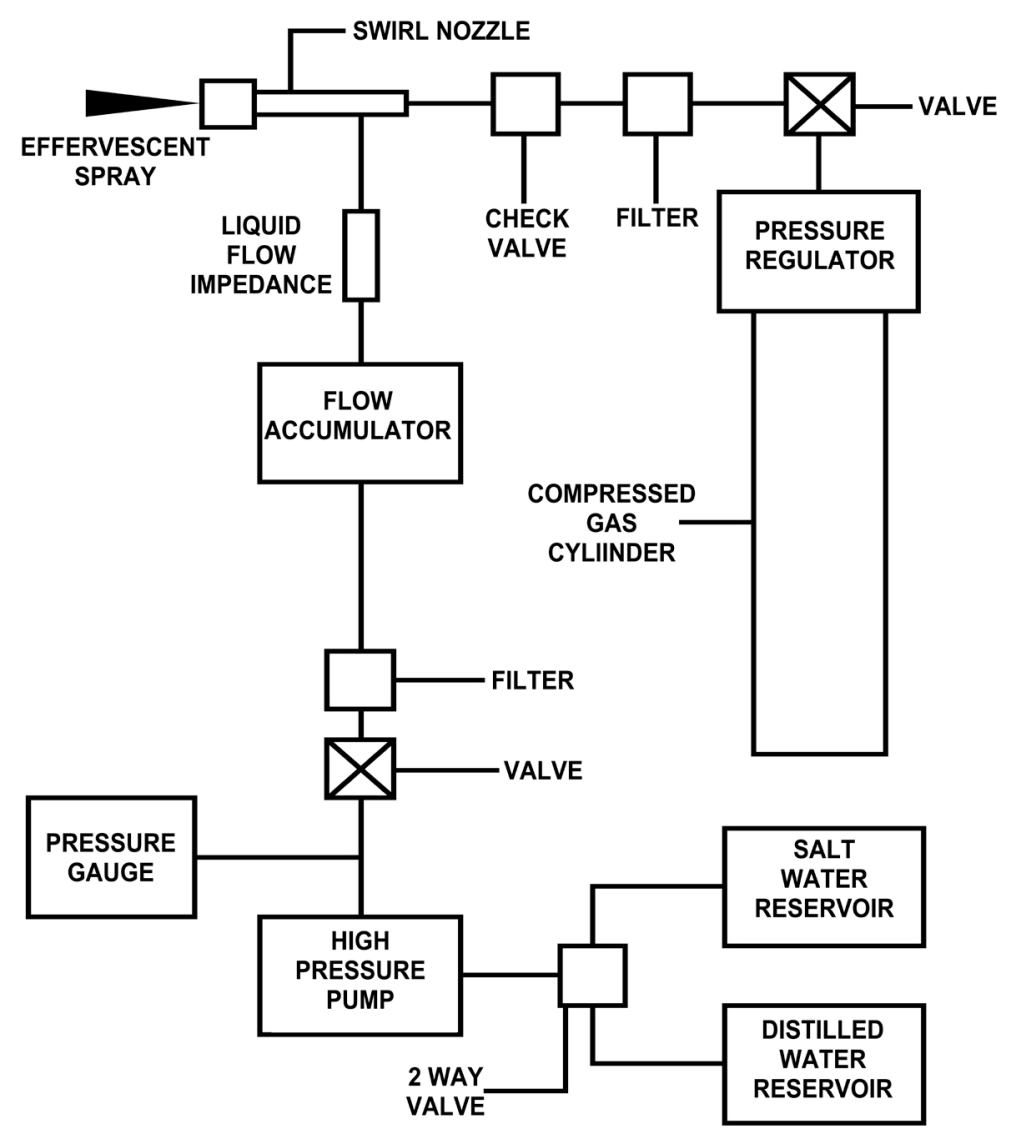

Figure 7. Schematic of the improved effervescent spray apparatus. 
The aerosol measuring instrument setup is shown in Figure 8. The particle sizing instruments were situated at the bottom of the instrument stand. At the lower left a vertical pipe takes in the sample. The bottom of the pipe fed the sample directly into the large particle measuring instrument, TSI APS. The input was simultaneously sent off via a tee fitting to the small particle measuring instrument on the right, TSI SMPS.

The TSI APS model 3321 [15] was for measuring aerosols in the $0.5-20 \mu \mathrm{m}$ range using aerodynamic time of flight measurement. The TSI SMPS [12] composed of a standard instrument combination of the TSI classifier model 3080/3081 DMA [13] and the TSI Condensation Particle Counter CPC model 3010 [14], was for measuring aerosols in the $20-700 \mathrm{~nm}$ range. The APS was calibrated by TSI two weeks before the experiment described below.

Two computers were on the top or the instrument stand, the one on the left controls the APS and the one on the right controls the SMPS. Raw data from an experiment is shown on their screens with different magnitude scaling. The APS shows the long drop off of particles from $\sim 0.5 \mu \mathrm{m}$ to $\sim 20 \mu \mathrm{m}$. The SMPS shows the distribution from $\sim 20 \mathrm{~nm}$ to $\sim 700 \mathrm{~nm}$. Both instruments were calibrated with various polystyrene spheres of known size. This setup provides a significant detection range overlap between the two instruments and allows data correlation across the entire particle size range of interest.

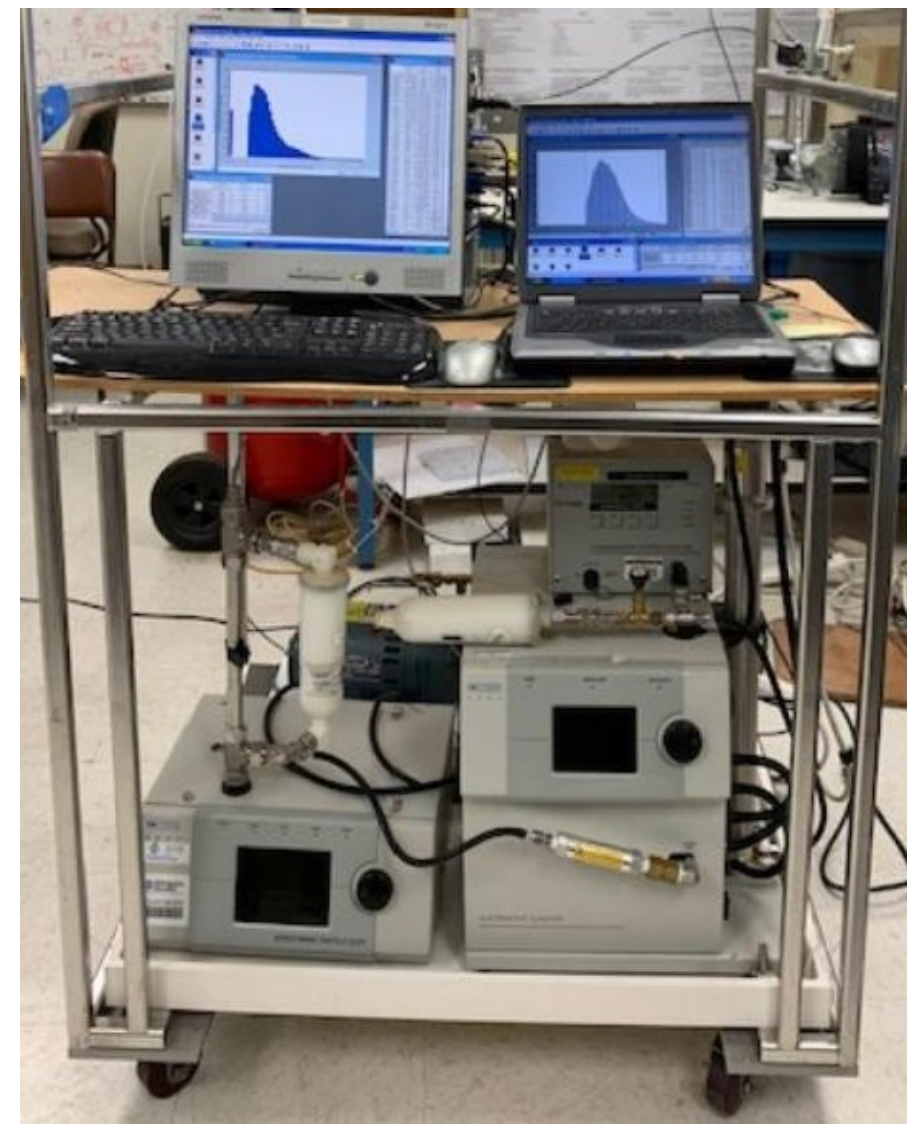

Figure 8. Aerosol measuring instrument setup. 


\section{Experimental Results}

Results are presented in two parts. First the measurements of gas and brine pressure and flows and calculations are presented, then these are compared with calculated results using the theoretical mixed flow nozzle Equations (1) and (5).

\subsection{Nozzle Flow}

An experiment, labeled 5 will be described. Figure 7 showed a schematic of the experimental apparatus. A nitrogen cylinder provided nitrogen gas, (a surrogate for air), with a regulated output pressure of $P_{o}=300 \mathrm{~b}$. A high-pressure pump provided brine of concentration, $C_{b}=0.032$ and pressure of approximately $305 \mathrm{~b}$. The fluids flowed into a swirl nozzle with a $200 \mu \mathrm{m}$ diameter sapphire orifice.

The $11.3 \mathrm{ml}$ volume pump piston operated with a cycle time of $3.37 \mathrm{~s}$ for a brine liquid flow rate, $F_{b}=3.353 \mathrm{ml} / \mathrm{s}$. The air flow, $F_{a}=53 \mathrm{l} / \mathrm{min}$ was measured with a TSI model 3063 gas flow meter at atmospheric pressure, $P_{a t m}=1.0133 \mathrm{~b}$, after gravitational separation.

Using the air surrogate nitrogen gas density and speed of sound at atmospheric pressure and $20^{\circ} \mathrm{C}, \rho_{a}=1.165 \mathrm{~kg} / \mathrm{m}^{3}, a_{n}=349 \mathrm{~m} / \mathrm{s}$ and the brine density $\rho_{b}$ $=1020 \mathrm{~kg} / \mathrm{m}^{3}$, the gas to liquid ratio, GLR was,

$$
\mathrm{GLR}=\frac{\rho_{a} F_{a}}{\rho_{b} F_{b}}=0.3
$$

The critical pressure at the nozzle outlet, $P_{c}$ from Equation (2) was $158.5 \mathrm{~b}$.

The pressure jump, $\Delta P$ from Equation (3) was $141.5 \mathrm{~b}$.

The volume air flow at the nozzle exit was,

$$
F_{a e}=\frac{F_{a} P_{a t m}}{P_{c}}=0.339 \mathrm{l} / \mathrm{min} .
$$

The combined gas and liquid flow at the exit,

$$
F_{\text {mix }}=F_{a e}+F_{b}=0.540 \mathrm{l} / \mathrm{min} .
$$

The proportion of gas flow by volume at the exit,

$$
x=\frac{F_{a e}}{F_{\text {mix }}}=0.627 .
$$

From Equation (4) the density of the nitrogen at the critical exit pressure was, $\rho_{a c}=182 \mathrm{~kg} / \mathrm{m}^{3}$.

From Equation (1) with $\rho_{b}=1020 \mathrm{~kg} / \mathrm{m}^{3}$, the exit speed of sound of the mixed flow, $a_{m i x}=266.7 \mathrm{~m} / \mathrm{s}$.

With the nozzle diameter $d=200 \mu \mathrm{m}$, the calculated mixed flow volume at the exit, $S_{\text {mix }}$ from Equation (2) was $0.518 \mathrm{l} / \mathrm{min}$.

The discharge coefficient for nozzle,

$$
D_{\text {coef }}=\frac{F_{\text {mix }}}{S_{\text {mix }}} .
$$

was 1.04 . 
Therefore, the measured flow and the calculated flow are within $4 \%$ of each other. These results show that the mixed flow model from Equation (1) is a good representation of the actual nozzle flow.

\subsection{Experimental Particle Measurements}

The room was cleaned of background particles with HEPA filters and fans. The room relative humidity was measured at $42 \%$ before and after the experiment. Below 45\% RH salt brine particles will efflorescence to a dry minimum size salt crystal [18]. The particle sizer diameters were, therefore, the dry salt particle.

The swirl nozzle was operated for only approximately 45 seconds, then the particle sizers were started. The SMPS recorded 3 scans from $14.1 \mathrm{~nm}$ to 736.5 $\mathrm{nm}$ particle diameter, each scan taking 4.5 minutes. The APS recorded nearly continuously and data was saved at approximately 2 minutes after the start of each SMPS scan. The APS record was aerodynamic corrected for channel geometry as required by the instrument. After correction the APS data record spanned particle diameters from $360 \mathrm{~nm}$ to $13,454 \mathrm{~nm}$. Each instrument also calculated the mass for each particle using density data entered into the instruments. The data from the SMPS and APS instruments were entered into EXCEL and analyzed.

Data taken for experiment 5 consisted of three SMPS 4.5-minute scans numbered 13,14, and 15 and one APS reading per SMPS scan at approximately 2 minutes in the scan. The sizer data was entered at each particle diameter bin center from SMPS and APS histogram bins for the number of particles per $\mathrm{cm}^{3}$, $\mathrm{dN}$, and the sizers calculated mass, ug per $\mathrm{cm}^{3}, \mathrm{dM}$. The bin width, $\mathrm{dw}$ varies from $0.5 \mathrm{~nm}$ to $26.6 \mathrm{~nm}$ for the SMPS and from $26 \mathrm{~nm}$ to $987 \mathrm{~nm}$ for the APS. The EXCEL calculated values for particles $/ \mathrm{cm}^{3}$ per $\mathrm{nm}, \mathrm{dN} / \mathrm{dw}$ are shown in Figure 9 and for mass, ug/ $\mathrm{cm}^{3}$ per $\mathrm{nm}, \mathrm{dM} / \mathrm{dw}$ are shown in Figure 10 versus particle diameter for scan 13.

In Figure 10, the mass is concentrated in larger particles with a peak at about $3500 \mathrm{~nm}$. When we compare this with the many experiments described in Sovani [11], the mass distribution in the larger particle ranges is similar to what was formerly observed. The small particles were probably not observed before because there were no instruments used at the time which could detect them. We hypothesize that nano particles have always been produced by effervescent spray but were not detected previously because no one could see or was looking for them.

The calculated values for the three consecutive scans labeled 13, 14, and 15 for the SMPS and the APS are shown in Figure 11 and Figure 12 in log-log plots of particle size in $\mathrm{nm}$ versus particles $/ \mathrm{cm}^{3}$ per $\mathrm{nm}, \mathrm{dN} / \mathrm{dw}$ and mass, ug/ $\mathrm{cm}^{3}$ per $\mathrm{nm}, \mathrm{dM} / \mathrm{dw}$.

The overlap area between the SMPS and the APS for $\mathrm{dN} / \mathrm{dw}$ is shown in a linear plot in Figure 13. APS data is not accurate at the lower particle sizes. However, notice the overlap is close to the largest SMPS particle size data point. 


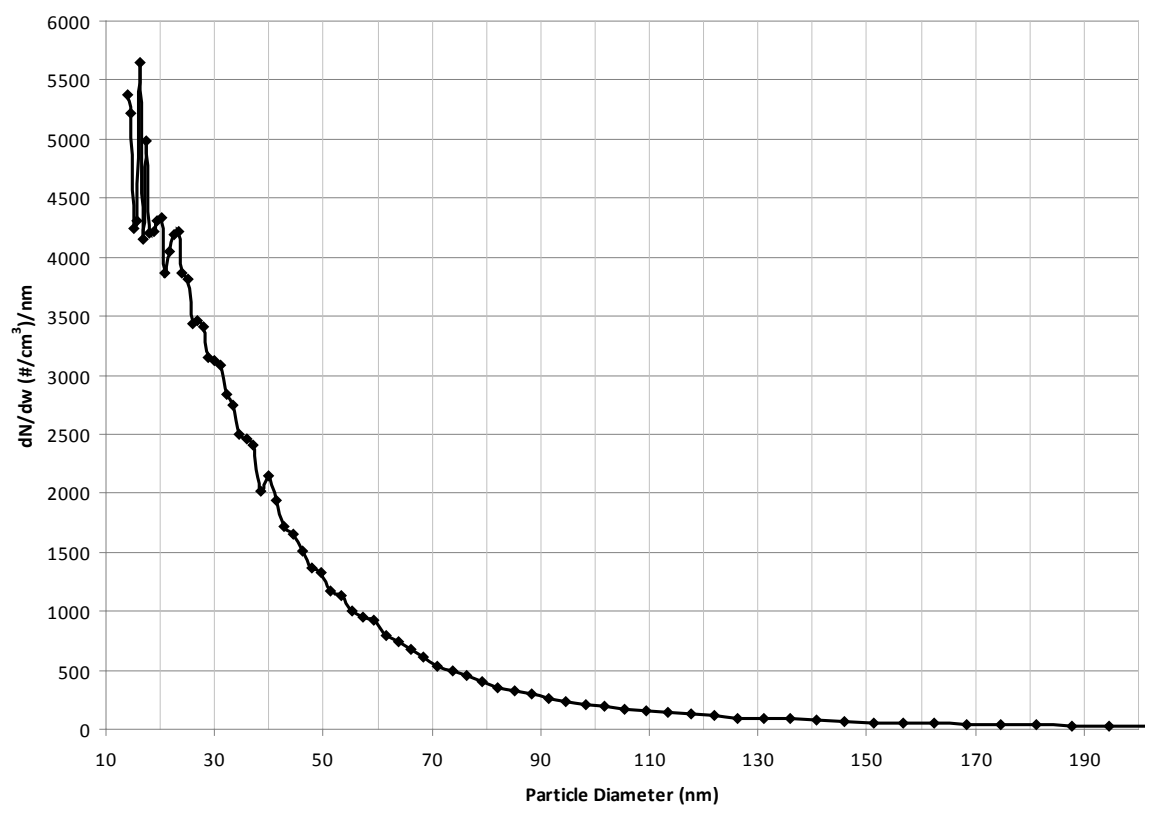

Figure 9. dN/dw data for first scan 13 of experiment 5.

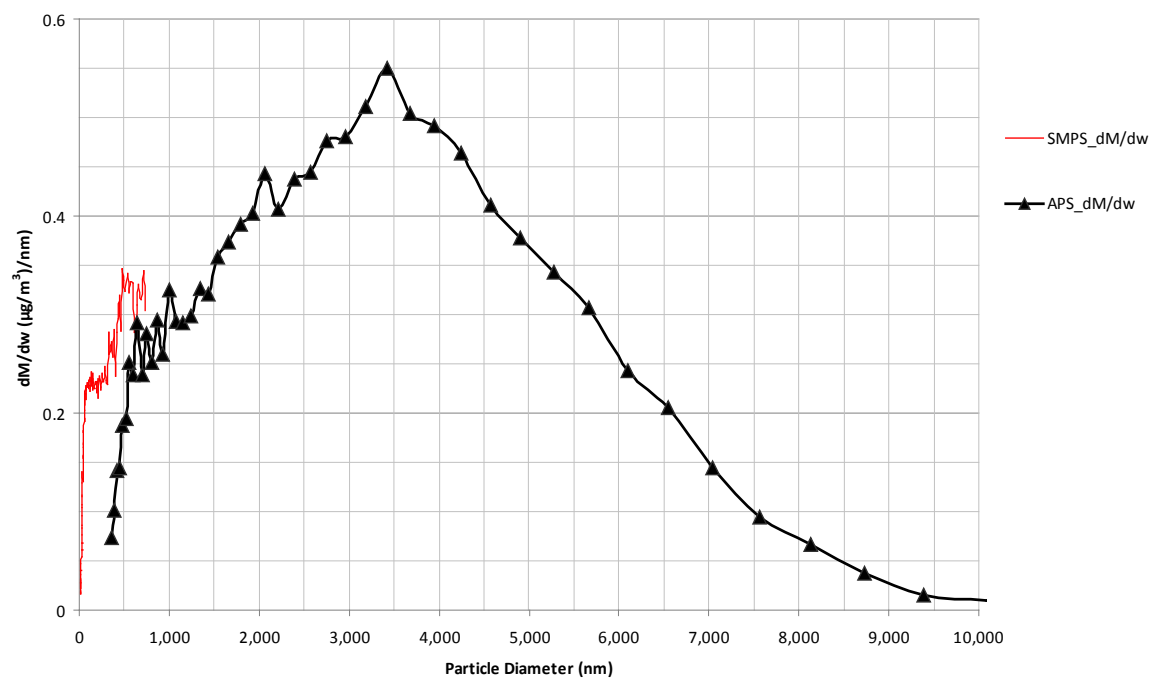

Figure 10. dM/dw data for first scan 13 of experiment 5.

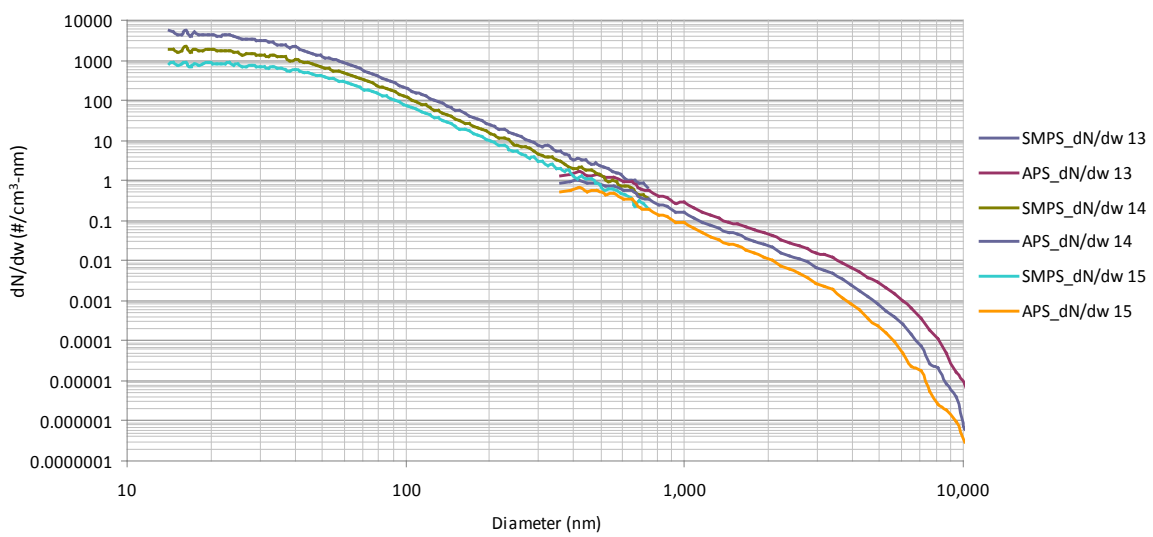

Figure 11. dN/dw versus particle diameter for experiment 5. 


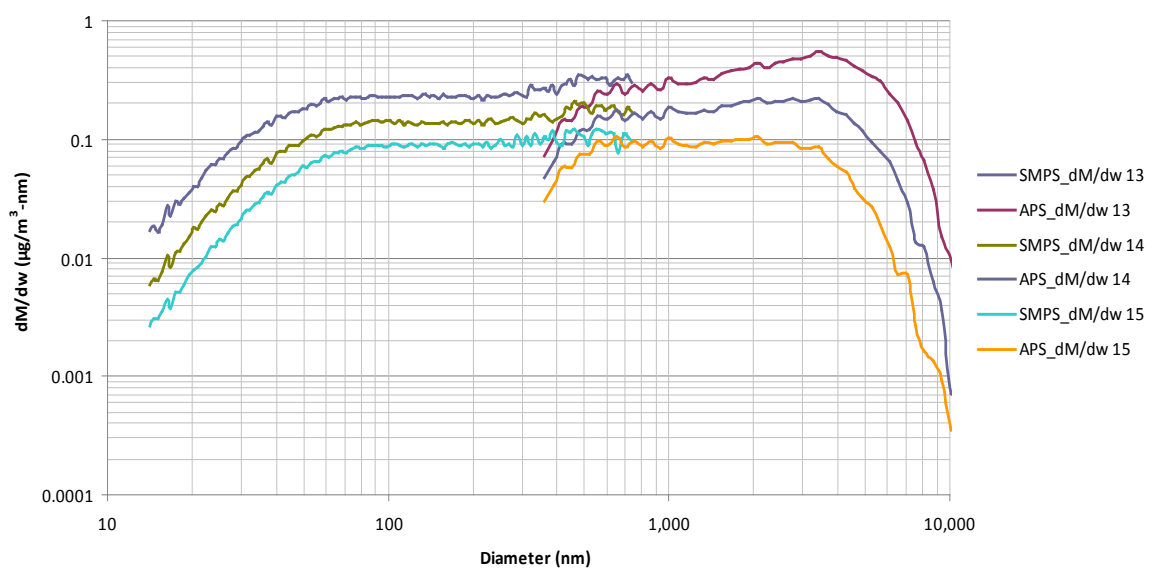

Figure 12. dM/dw versus particle diameter for experiment 5.

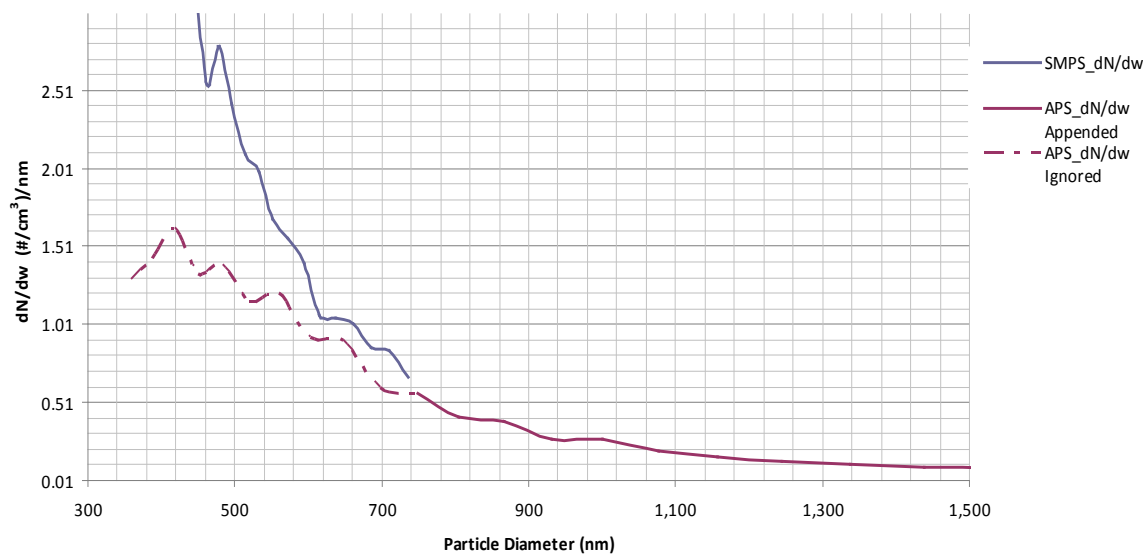

Figure 13. $\mathrm{dN} / \mathrm{dw}$ versus particle diameter linear scale near overlap of SMPS and APS data for experiment 5 .

APS data less than this SMPS data is ignored to combine the SMPS and APS bin data to get data for the full range. APS data for center bin sizes from $749.1 \mathrm{~nm}$ to $13,454 \mathrm{~nm}$ was appended to the SMPS data.

Figure 14 shows the bin counts versus particle size of the combined data. The bin count for the APS has been adjusted to match bin sizes. An estimate was made that particle sizes from $34.6 \mathrm{~nm}$ to $495 \mathrm{~nm}$ are usable for MCB, those less than $33.4 \mathrm{~nm}$ are too small and those greater than $495 \mathrm{~nm}$ are too big. These limits are shown in Figure 14.

\subsection{Analysis of Experimental Particle Measurements}

The EXCEL analysis of the particle sizer measurements calculated various quantities. The sums from all the bins for particles, $N_{p}$ and for mass, $M_{p}$ were calculated. The ratio of the sum of estimated MCB usable particles from $35 \mathrm{~nm}$ to 495 $\mathrm{nm}$ diameters to sum of total particles, $R_{u p}$ was calculated. The first scan 13 had the following results, the sums of total numbers of dry particles, $N_{p}=148129.8$ $\# / \mathrm{cm}^{3}$, total of particle mass, $M_{p}=2.71545 \times 10^{-6} \mathrm{mg} / \mathrm{cm}^{3}$, and the ratio of sum of usable portion to sum of all particles, $R_{u p}=0.467$. The brine salt concentration, 


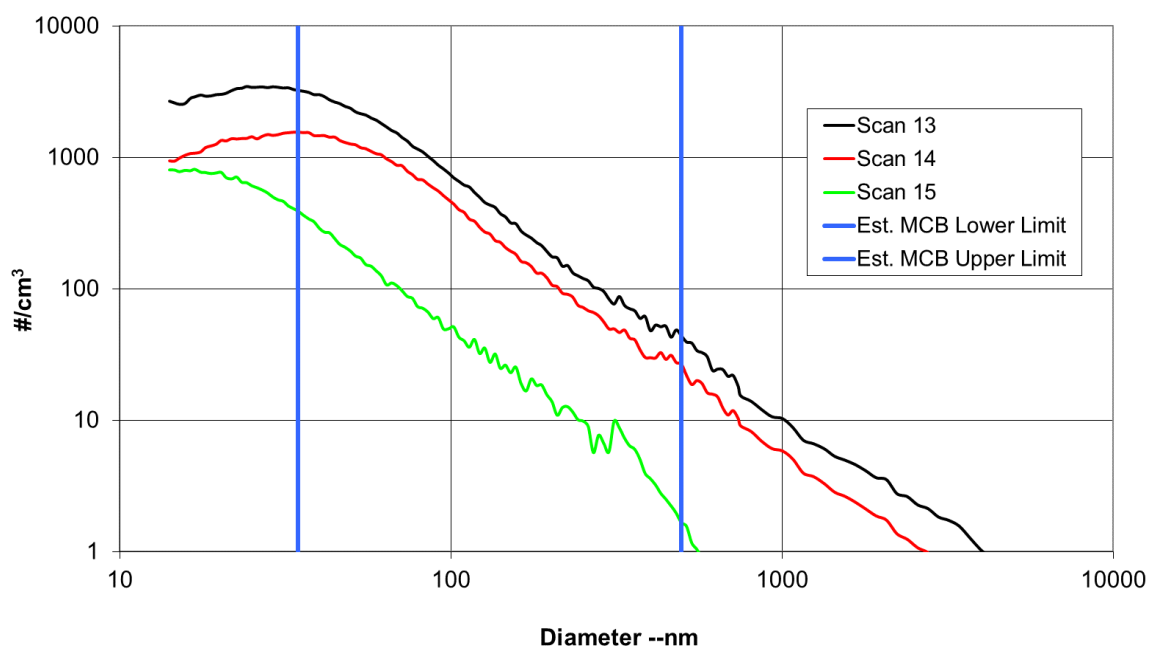

Figure 14. Bin particle count versus diameter for experiment 5.

$C_{b}$ the density of the brine, $\rho_{b}$, and the experimental brine measured flow, $F_{b}$, were combined with the particle sizer results and analyzed.

The average wet brine particle volume,

$$
V_{w b}=\frac{\frac{M_{p}}{N_{p}}}{C_{b} \rho_{b}},
$$

was $5.61629 \times 10^{-19} \mathrm{~m}^{3}$.

The number of MCB usable wet brine particles,

$$
N_{u b}=\frac{R_{u b} F_{b}}{V_{w b}},
$$

was $2.78960 \times 10^{12}$ particles $/ \mathrm{s}$.

Various quantities for $10^{15}$ usable particles/s were calculated.

The number of nozzles, required,

$$
N_{\text {noz }}=\frac{10^{15}}{N_{u b}}
$$

was 358 .

The brine flow required,

$$
F_{b 15}=F_{b} N_{\text {noz }}
$$

was $1.2 \mathrm{l} / \mathrm{s}$.

The power required for isentropic compression [19] of the gas,

$$
P W_{a}=N_{\text {noz }}\left(F_{a} P_{a t m}\left(\frac{k}{k-1}\right)\right)\left(\left(\frac{P_{o}}{P_{a t m}}\right)^{\frac{k-1}{k}}-1\right),
$$

was $457 \mathrm{kw}$.

The power required for brine flow,

$$
P W_{b}=N_{\text {noz }} F_{b}\left(P_{o}+P_{a t m}\right),
$$


was $35.9 \mathrm{kw}$.

The total power required,

$$
P W_{\text {total }}=P W_{a}+P W_{b} \text {, }
$$

was $493 \mathrm{kw}$.

\subsection{Experimental Particle Count Variation with Time}

Time data, for experiment 5 from the SMPS and APS particle sizers, were entered into EXCEL particle sizer analysis. Analysis showed the center of particle diameter for the small particle count distribution occurred 4 seconds after the start of each SMPS scan. The particle diameter center of the usable particle count distribution occurred 2 minutes 13 seconds after the start of each SMPS scan and the large particle count APS measurement occurred at 1 minute 55 seconds after the start of each SMPS scan. The total particle bin count for each distribution is considered to occur at these times in the following study.

Figure 15 shows the decrease in number of particles per $\mathrm{cm}^{3}$ over time due to loss of particles by dilution mixing into the large room, by particle loss through impact with stirring fans, walls, or other ways. The three points on each curve are for the measurements of scans 13,14, and 15.

Figure 16 shows for scan 13,14, and 15 the ratio of the number of usable particles relative to the total number of particles increased from 0.467 to 0.585 of the total while the number of small particles relative to total particles reduced by 0.529 to 0.41 . This indicates that coagulation of very small particles is potentially producing usable particles and will reduce the number of nozzles required for $10^{15} / \mathrm{s}$. The number of large particles relative to total particles remained low around 0.005 .

Figure 17 shows that the ratio of mass of large particles relative to mass of total particles. A very small number of large particles, $\sim 0.5 \%$ relative to the total

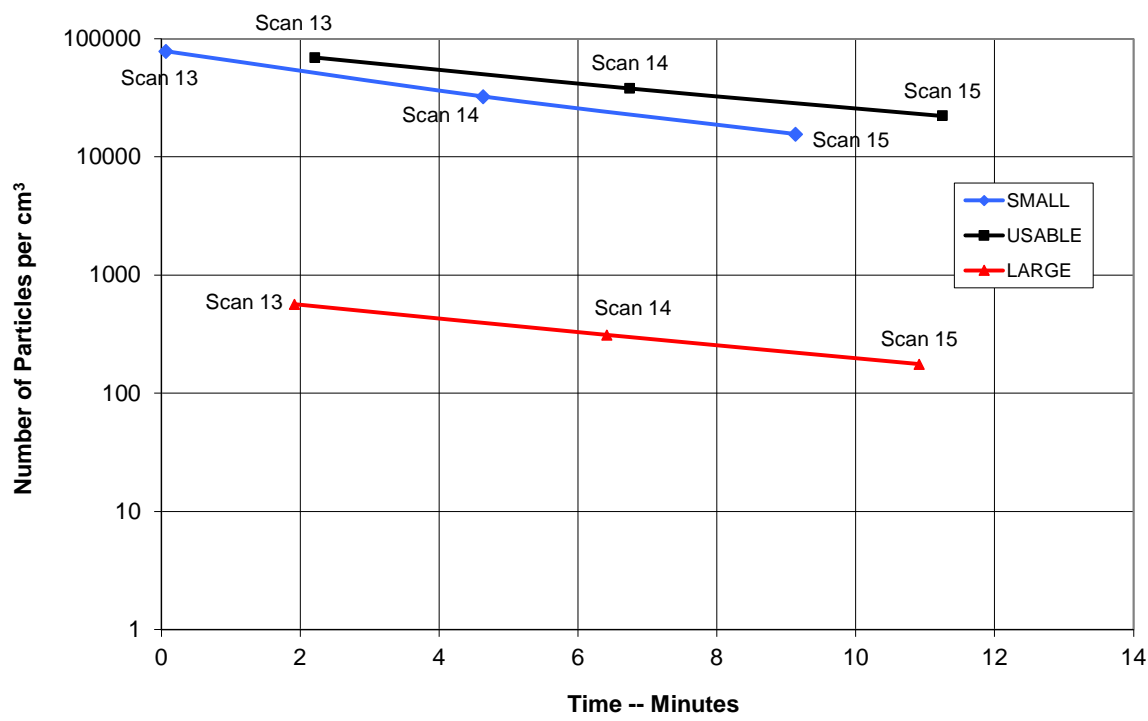

Figure 15. Effects of mixing and losses in large room on number of particles versus time. 
RATIO OF PARTICLES TO TOTAL

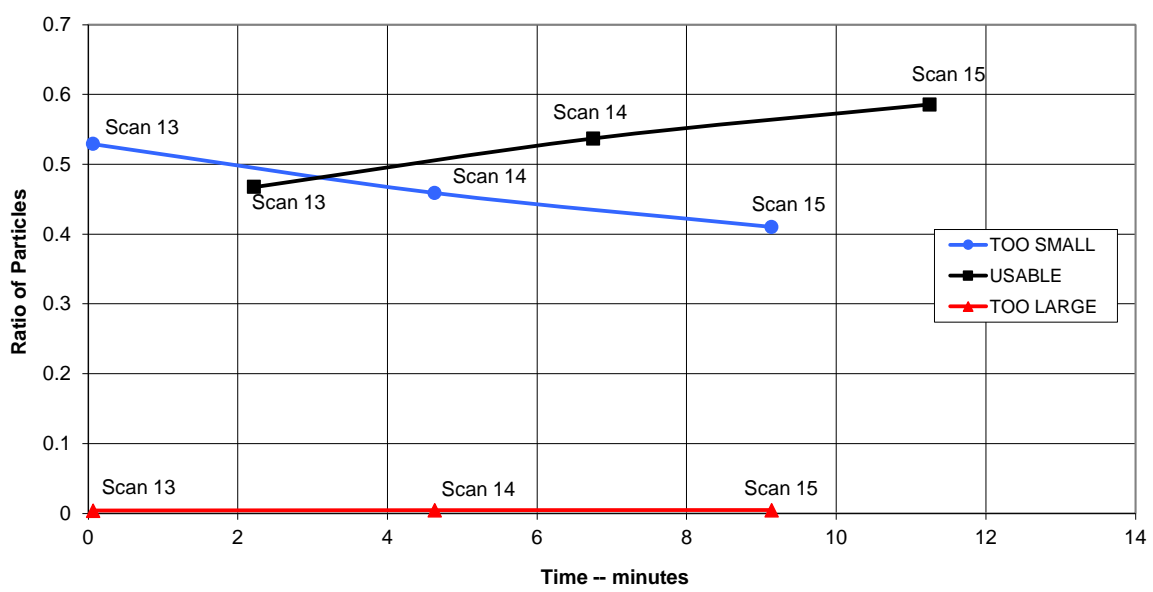

Figure 16. Ratio of number of small, usable, and large particles versus time.

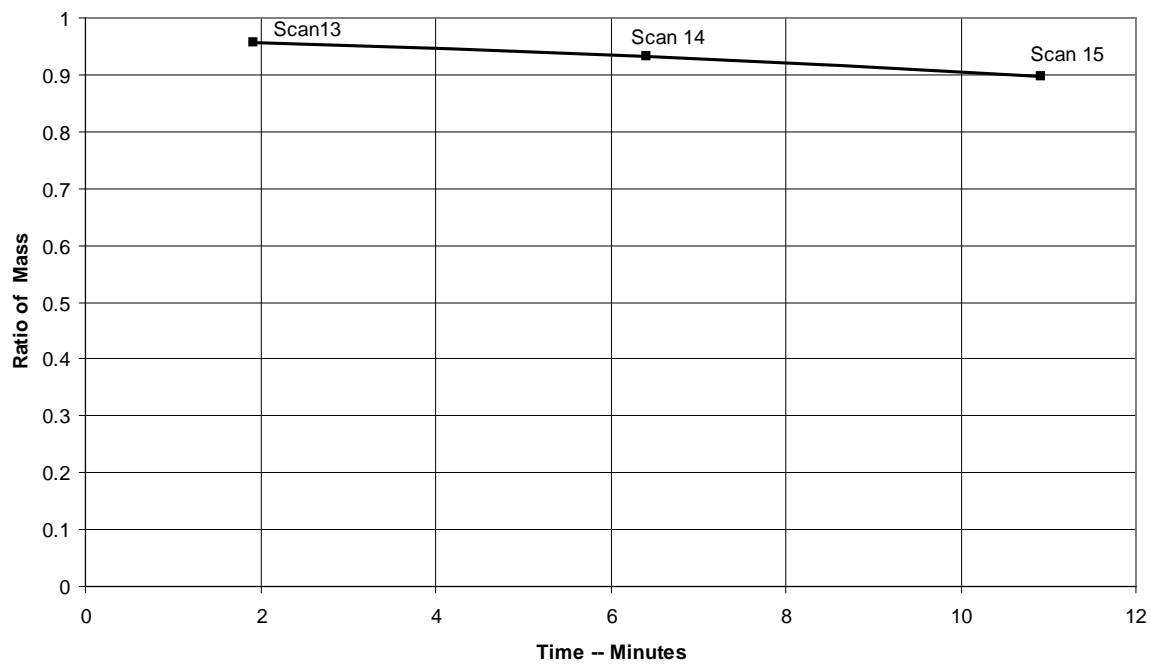

Figure 17. Ratio of mass of large particles to mass of total particles versus time.

number, carries more than $90 \%$ of the total brine mass. If the large particles have a negative effect on MCB or if evaporative cooling hinders particle rise, an impactor to filter out the larger particles [20] [21] may be required.

\section{Model for Improving Nozzle Design}

An equation for the product $C_{b} \rho_{b} F_{b 15}$ which involves only the equations of the particle sizer analysis can be developed by substituting into Equation (14), $N_{\text {noz }}$ from (13) then $N_{u b}$ from (12) and then $V_{w b}$ from (11)

$$
C_{b} \rho_{b} F_{b 15}=10^{15} \frac{M_{p}}{R_{u p} N_{p}}=37.86 \mathrm{kgl} / \mathrm{sm}^{3}
$$

A summary EXCEL spreadsheet was used to calculate the average value for this equation from results calculated in EXCEL particle sizer analyses for 24 ex- 
periments. This equation had about constant value for these experiments which included pressure variations from $30 \mathrm{~b}$ to $300 \mathrm{~b}$ and nozzle area for diameters variations from $200 \mu \mathrm{m}$ to $300 \mu \mathrm{m}$. Only nozzle particle spray characteristics are involved in this constant which would be expected if the nozzle sprays are always similar.

Equation (18) with the constant from particle measurement data and the results from mixed fluid flow equations (1) and (5) can be used for a model to predict nozzles performance. An EXCEL spread sheet was constructed for the model. The constants for the model, atmospheric pressure, $P_{a t m}$ atmospheric density, $\rho_{\text {atm }}$, brine speed of sound, $a_{b}$, and air speed of sound, $a_{a}$, are entered. The variables, nozzle area, $A_{\text {noz }}$, brine concentration, $C_{b}$, brine density, $\rho_{b}$, GLR, and stagnation pressure, $P_{o}$, are chosen. A trial guess is made for the number of nozzles, $N_{\text {no⿱ }}$ required for $10^{15}$ particles/s, to solve the model. The brine flow for one nozzle, $F_{b}$, is calculated with Equation (14), with the constant, $C_{b} \rho_{b} F_{b 15}$ the brine density, $\rho_{b}$, and brine concentration, $C_{b}$. Choked nozzle exit air pressure, $P_{c}$ is calculated from stagnation pressure, $P_{o}$ with Equation (2). Air density at nozzle exit, $\rho_{a c}$ is calculated from choked pressure, $P_{\circ}$ atmospheric air density, $\rho_{a t m}$, and atmospheric pressure, $P_{\text {atm }}$, from Equation (4). Atmospheric pressure air flow, $F_{a}$, is calculated from brine flow, $F_{b}$, brine density, $\rho_{b}$, GLR, and atmospheric air density, $\rho_{a t m}$, with Equation (6). Air flow at choked nozzle exit, $F_{a e}$ is calculated using choked exit pressure, $P_{\mathfrak{c}}$ atmospheric air flow, $F_{a}$, and atmospheric air pressure, $P_{a t m}$, from Equation (7). Total mixed flow, $F_{m i x}$ of brine, $F_{b}$ plus air, $F_{a c}$ at exit is calculated with Equation (8). Air volume ratio, $X$, at the exit is calculated using $F_{a e}$ and $F_{m i x}$ with Equation (9). This completes the calculation of the mixed flow with the constant, $C_{b} \rho_{b} F_{b 15}$, from particle measurements and the flow equations. The choked flow is then calculated to compare. The mixed flow speed of sound, $a_{m i x}$ is calculated using the air volume ratio at exit, $x$, the speed of sound of the brine, $a_{b}$, the speed of sound of air, $a_{a}$, the density of air at nozzle exit, $\rho_{a c}$ and the density of the brine, $\rho_{b}$, with Equation (1). The theoretical mixed air and brine choked flow $S_{m i x}$ is calculated from the speed of sound, $a_{m i x}$ at the exit and the nozzle area, $A_{\text {nов }}$ with Equation (5). Nozzle coefficient is calculated using $F_{m i x}$ and $S_{m i x}$ from Equation (10). The power required is calculated from Equations (15), (16), and (17). The trial number of nozzles is changed and the calculations repeated until the nozzle coefficient is about 0.99 but less than one for the calculations to match. Note that if instead of $10^{15}$ we had wanted $10^{16}$ as the target particles/s an identical derivation for $C_{b} \rho_{b} F_{b 16}$ would give the similar equation with $379 \mathrm{kgl} / \mathrm{m}^{3}$ as the constant.

The EXCEL model was calculated using the data from experiment 5 . The results are shown in Table 1. The calculated brine flows and air flows are close to the original experiment. The number of nozzles required for $10^{15}$ particles/s was calculated as 352 , close to the experiment data of 358 . The total power calculated was $461 \mathrm{kw}$ close to the $493 \mathrm{kw}$ result from the original experiment measurement. This shows the model works. 
Table 1. EXCEL results for model with experiment 5 parameters.

\begin{tabular}{|c|c|c|c|c|}
\hline \multicolumn{5}{|l|}{ Constants } \\
\hline$C_{b} \rho_{b} F_{b 15}$ & 37.86 & $\mathrm{kgl} / \mathrm{sm}^{3}$ & & \\
\hline$P_{a t m}$ & 1.01 & $\mathrm{~b}$ & & \\
\hline$\rho_{\text {atm }}$ & 1.21 & $\mathrm{~kg} / \mathrm{m}^{3}$ & & \\
\hline$a_{a}$ & 346.00 & $\mathrm{~m} / \mathrm{s}$ & & \\
\hline$a_{b}$ & 1500.00 & $\mathrm{~m} / \mathrm{s}$ & & \\
\hline Variables & & & round & $\mathrm{m}$ \\
\hline$A_{\text {noz }}$ & $3.24 \mathrm{E}-08$ & $\mathrm{~m}^{2}$ & diameter & 0.000203 \\
\hline$C_{b}$ & 0.032 & & & \\
\hline$\rho_{b}$ & 1020.00 & $\mathrm{~kg} / \mathrm{m}^{3}$ & & \\
\hline$G L R$ & 0.30 & & & \\
\hline$P_{o}$ & 300.00 & $\mathrm{~b}$ & & \\
\hline trial $N_{n o z}$ & 352.00 & & & \\
\hline \multicolumn{5}{|c|}{ Calculations } \\
\hline$F_{b 15}$ & 1.16 & $1 / \mathrm{s}$ & 3.30 & $\mathrm{ml} / \mathrm{s}$ \\
\hline$F_{b}$ & 0.20 & $1 / \min$ & & \\
\hline$P_{c}$ & 158.48 & $\mathrm{~b}$ & & \\
\hline$\rho_{a c}$ & 188.48 & $\mathrm{~kg} / \mathrm{m}^{3}$ & & \\
\hline$F_{a}$ & 50.21 & $1 / \min$ & & \\
\hline$F_{a e}$ & 0.32 & $1 / \min$ & & \\
\hline$F_{\text {mix }}$ & 0.52 & $1 / \min$ & & \\
\hline$x$ & 0.619 & & & \\
\hline$a_{\text {mix }}$ & 267.78 & $\mathrm{~m} / \mathrm{s}$ & & \\
\hline$S_{m i x}$ & 0.52 & $1 / \mathrm{min}$ & & \\
\hline$D_{c o e f}$ & 0.9976 & & & \\
\hline$P W_{a}$ & 426.53 & & & \\
\hline$P W_{b}$ & 34.68 & & & \\
\hline$P W_{\text {total }}$ & 461.21 & & & \\
\hline
\end{tabular}

\subsection{Model Nozzle Design with Higher Salt Concentration}

All of our experiments were with a salt brine concentration of $C_{b}=0.032$, but changing the brine concentration, such as to 0.1 , should produce a minimum change in the spray. The Reynolds number for the brine flow will be 0.91 lower because of higher kinematic viscosity. The Reynolds number of the brine flow through each of the tangential holes shown entering the mixing chamber in Figure 5 is less than 200 and very laminar. The air flowing through the mixing chamber is very turbulent and has a Reynold number greater than $10^{10}$. There 
will be little change in the nozzle spray. Surface tension will be 1.03 higher which will slightly increase anulus attachment to the nozzle. The sprayed brine should be very similar but will produce 2.85 times greater brine mass for each dry particle and 1.76 times greater diameter. The $\mathrm{dN} / \mathrm{dw}$ graph in Figure 9 will be shifted to larger diameters. This will result in the estimated usable particles from 34.6 to $495 \mathrm{~nm}$ being replaced by those from $19.7 \mathrm{~nm} 286 \mathrm{~nm}$ but with higher masses and shifted to the 34.6 to $495 \mathrm{~nm}$ diameters due to the increased brine concentration. Making these changes for the EXCEL particle data spread sheet from experiment 5, produced expected results. Total Power required went down, number of nozzles went down, ratio of MCB usable particles went up, and larger particle mass went up.

To check if the effects will be similar at lower pressure. Data for lower pressure is shown in $\mathrm{dN} / \mathrm{dw}$ data for a $35 \mathrm{~b}$ experiment in Figure 18 . This is similar to the 300b experiment shown in Figure 9 except there are fewer very small particles. The effect of changing salt concentration to 0.1 , will be the same as above for $300 \mathrm{~b}$.

Salt concentration to even higher values will have similar effects. For example, changing the salt concentration to 0.2 should also produce a minimum change in the spray. Reynolds number for brine will be 0.76 lower because of higher kinematic viscosity. Surface tension will be 1.07 higher which will slightly increase anulus attachment to the nozzle. The sprayed brine should have very similar characteristics but will have about 5.71 times greater mass of salt in each brine particle. The dry salt particles will be about 2.21 larger. The $\mathrm{dN} / \mathrm{dw}$ graphs in Figure 18 or Figure 9 will be shifted to larger diameters. This will result in the estimated usable particles from $34.6 \mathrm{~nm}$ to $495 \mathrm{~nm}$ being replaced by those from $15.7 \mathrm{~nm}$ to $224 \mathrm{~nm}$ with the higher masses and diameters. The effect of changing to a 0.2 concentration should further decrease required power, decreased number of nozzles and increased mass of large particles.

Using the model to calculate effect of increasing brine concentration, should, therefore, be acceptable. For example, results of the model calculation for the total power versus brine concentration for 30b pressure are shown in Figure 19. Power was independent of nozzle diameter. The power decreased by 9.7 times with brine concentration increasing from 0.035 to 0.1 . Power decreased an additional 2 times for concentration increase from 0.1 to 0.2 . These are significant power decreases and suggest that increased brine should be considered. The effects of pressure and, nozzles diameter will be considered below.

Before considering additional predictions from the model in the next section, consider only changing the salt concentration for conditions of experiment 5 . Increasing the salt concentration to $C_{b}=0.1$ with density and $\rho_{b}=1070.7 \mathrm{~kg} / \mathrm{m}^{3}$ instead of 0.032 and 1020. Predictions for these inputs to the EXCEL model are shown in Table 2. The model predicts power decreases to $147 \mathrm{kw}$ compared with $494 \mathrm{kw}$ for the experiment and number of nozzles decreased from 358 to 115 . This shows the large effects of higher salt concentration. 


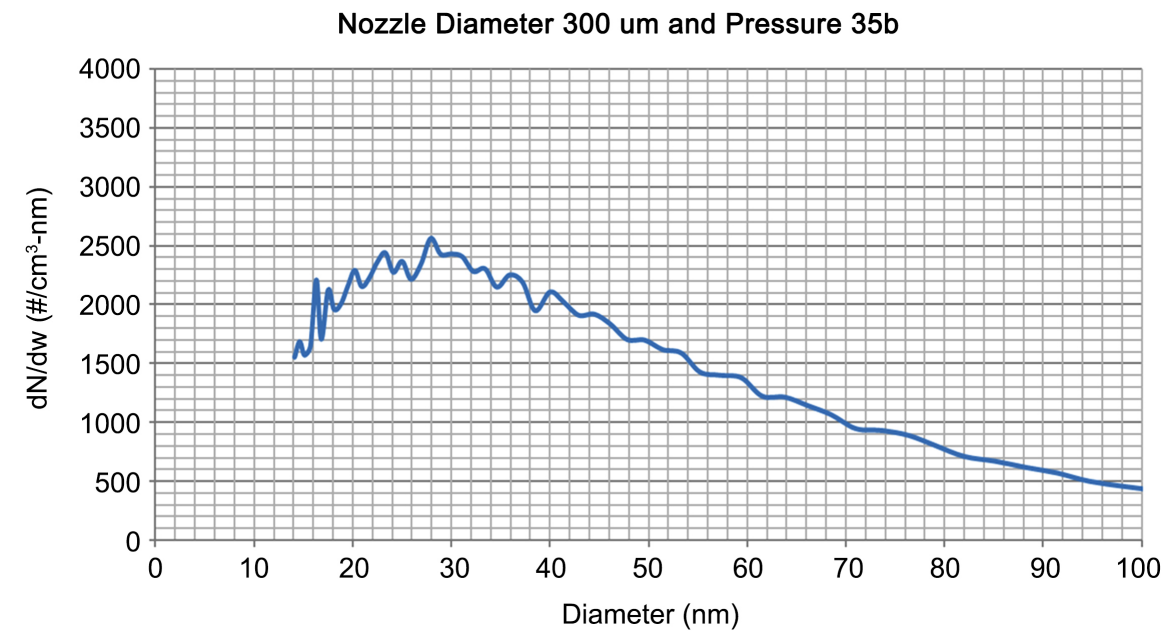

Figure 18. dN/dw data for pressure of $35 \mathrm{~b}$ and nozzle diameter of $300 \mu \mathrm{m}$.

MODEL PREDICTIONS for all Nozzle Dameters Power versus Brine Concentration at Pressure of $30 \mathrm{~b}$

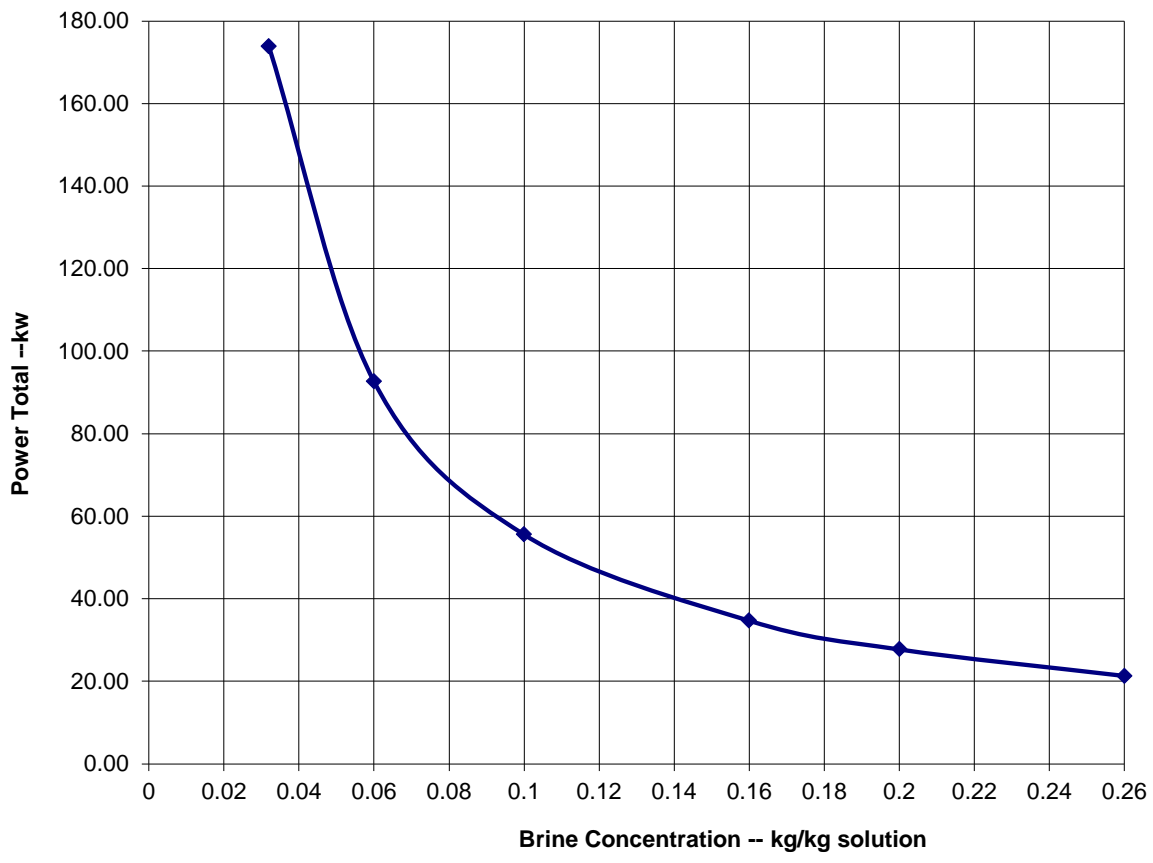

Figure 19. Power versus brine concentration in $\mathrm{kg} / \mathrm{kg}$ solution for $30 \mathrm{~b}$ pressure and all nozzle diameters.

\subsection{Model Nozzle Design with Lower Pressure and Greater Area}

The important effect of brine concentration on power required has been shown. The effects of pressure on power and number of nozzles will now be considered. Power to compress air was shown by equation 16 to be directly dependent on pressure and the model includes this.

Results from the model for variation of pressure from $30 \mathrm{~b}$ to $300 \mathrm{~b}$ for brine concentrations from 0.032 to 0.2 and a nozzle diameter of $500 \mu \mathrm{m}$ are shown in 
Figure 20. The strong effects of the brine concentration on power are again as shown in Figure 19. The power required also decreases by about $2.6 \times$ as the pressure decreases from $300 \mathrm{~b}$ to $30 \mathrm{~b}$ at all brine concentrations shown. The number of nozzles required increases by about $9 \times$ as pressure decreases from $300 \mathrm{~b}$ to $30 \mathrm{~b}$. The curves for brine concentration of 0.032 are similar to those obtained with our experiments which support the model.

For low total power operation, a high brine concentration and low pressure are best. For low number of nozzles, a high brine concentration and high pressure are best, but operation at lower pressure is advantageous because air pumps and plumbing are much more available and less expensive. Nozzle area will next be considered as a method to lower the number of nozzles at low pressure.

Table 2. EXCEL results for model with increased brine concentration.

\begin{tabular}{|c|c|c|c|c|}
\hline Constants & & & & \\
\hline$C_{b} \rho_{b} F_{b 15}$ & 11.96 & $\mathrm{kgl} / \mathrm{sm}^{3}$ & & \\
\hline$P_{\text {atm }}$ & 1.01 & $\mathrm{~b}$ & & \\
\hline \multirow[t]{2}{*}{$\rho_{\text {atm }}$} & 1.21 & $\mathrm{~kg} / \mathrm{m}^{3}$ & & \\
\hline & 346.00 & $\mathrm{~m} / \mathrm{s}$ & & \\
\hline$a_{b}$ & 1500.00 & $\mathrm{~m} / \mathrm{s}$ & & \\
\hline Variables & & & round & $\mathrm{m}$ \\
\hline$A_{\text {noz }}$ & $3.24 \mathrm{E}-08$ & $\mathrm{~m}^{2}$ & diameter & 0.000203 \\
\hline$C_{b}$ & 0.10 & & & \\
\hline$\rho_{b}$ & 1070.68 & $\mathrm{~kg} / \mathrm{m}^{3}$ & & \\
\hline$G L R$ & 0.30 & & & \\
\hline$P_{o}$ & 300.00 & b & & \\
\hline trial $N_{n o z}$ & 115.00 & & & \\
\hline \multicolumn{5}{|l|}{ Calculations } \\
\hline$F_{b 15}$ & 0.35 & $1 / \mathrm{s}$ & & \\
\hline$F_{b}$ & 0.18 & $1 / \mathrm{min}$ & 3.07 & $\mathrm{ml} / \mathrm{s}$ \\
\hline$P_{c}$ & 158.48 & $\mathrm{~b}$ & & \\
\hline$\rho_{a c}$ & 188.48 & $\mathrm{~kg} / \mathrm{m}^{3}$ & & \\
\hline$F_{a}$ & 49.18 & $1 / \mathrm{min}$ & & \\
\hline$F_{a e}$ & 0.31 & $1 / \min$ & & \\
\hline$F_{\text {mix }}$ & 0.50 & $1 / \mathrm{min}$ & & \\
\hline $\mathrm{x}$ & 0.630 & & & \\
\hline$a_{\text {mix }}$ & 263.02 & $\mathrm{~m} / \mathrm{s}$ & & \\
\hline$S_{\text {mix }}$ & 0.51 & $1 / \mathrm{min}$ & & \\
\hline$D_{\text {coef }}$ & 0.98 & & & \\
\hline$N_{\text {noz }}$ & 115.00 & & & \\
\hline$P W_{a}$ & 136.48 & & & \\
\hline$P W_{b}$ & 10.57 & & & \\
\hline$P W_{\text {total }}$ & 147.05 & & & \\
\hline
\end{tabular}


Model predictions of number of nozzles for $10^{15}$ particles per second and total power at $30 \mathrm{~b}$ pressure for various nozzle diameters and brine concentrations are shown in Figure 21. The number of nozzles goes down as the nozzle area goes up. The power is again constant for each brine concentration. Good experimental data up to $300 \mu \mathrm{m}$ is comparable with 0.032 brine concentration but larger areas have not been tested and may not spray particles as well.

MODEL PREDICTIONS for 500um Diameter Nozzle \# of Nozzles and Power versus Pressure \& Brine Concentration

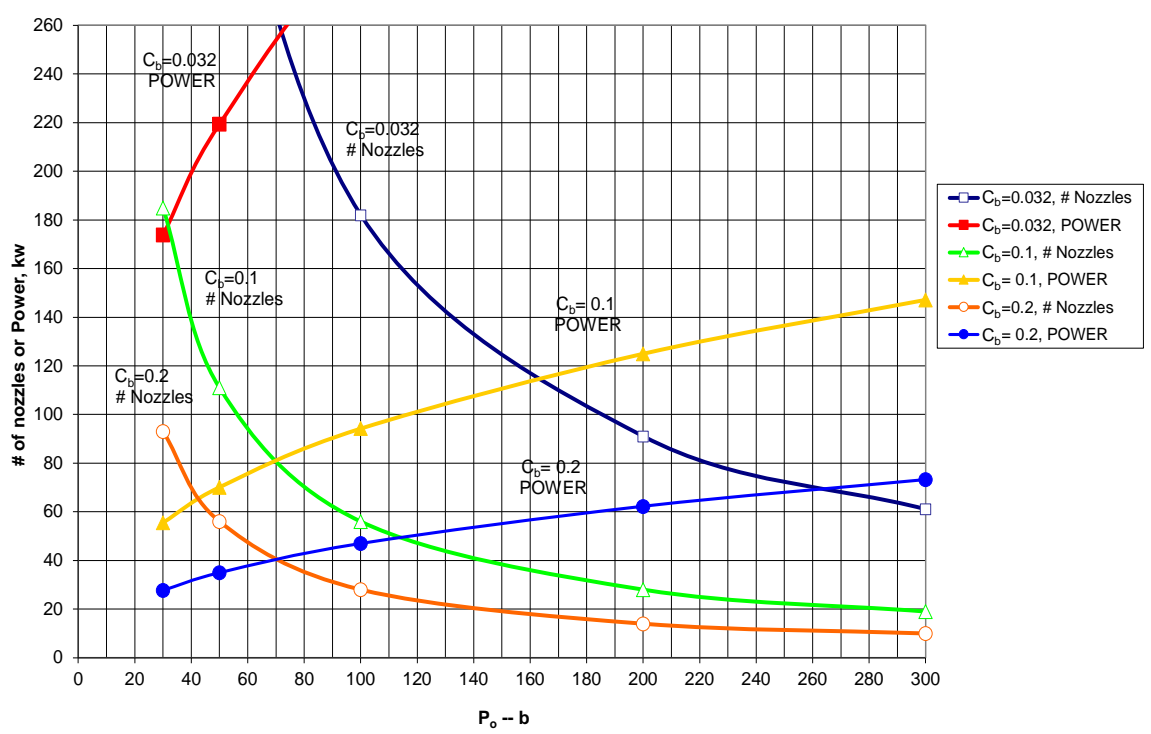

Figure 20. Model prediction of \# of nozzles and power required versus pressure for nozzel diameter of $500 \mu \mathrm{m}$ to produce $10^{15}$ particles/s.

MODEL PREDICTIONS

\# of Nozzles versus Nozzle Diameter

30b Pressure

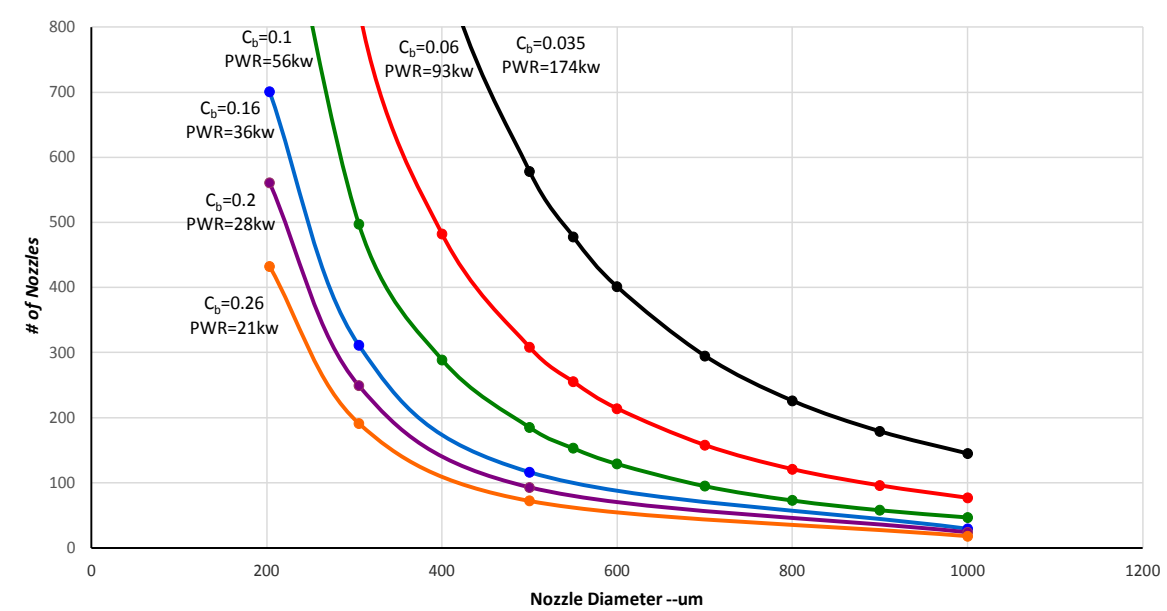

Figure 21. Model predictions of nozzles required to produce $10^{15}$ particles/s for various diameters and brine concentrations. 
Experimental data for nozzle diameters greater than $300 \mu \mathrm{m}$ was not available, but to consider a most desirable case, the model was used to predict the potential with higher brine concentration, low pressure and larger nozzle area. The EXCEL results from the model are shown in Table 3 for $1 \mathrm{~mm}$ diameter nozzle area at $30 \mathrm{~b}$ pressure and brine concentration of 0.1 and 0.2 . The predicted result is 48 nozzles and $56 \mathrm{kw}$ for $C_{b}=0.1$ and 24 nozzles and $28 \mathrm{kw}$ for $C_{b}=0.2$.

Table 3. EXCEL results for model with larger diameter and concentration.

\begin{tabular}{|c|c|c|c|c|}
\hline \multicolumn{5}{|l|}{ Constants } \\
\hline$C_{b}$ & 0.10 & & 0.20 & \\
\hline diameter & 0.001 & $\mathrm{~m}$ & 0.001 & $\mathrm{~m}$ \\
\hline$C_{b} \rho_{b} F_{b 15}$ & 37.86 & $\mathrm{kgl} / \mathrm{sm}^{3}$ & 37.85 & $\mathrm{kgl} / \mathrm{sm}^{3}$ \\
\hline$P_{a t m}$ & 1.01 & $\mathrm{~b}$ & 1.01 & $\mathrm{~b}$ \\
\hline$\rho_{a t m}$ & 1.21 & $\mathrm{~kg} / \mathrm{m}^{3}$ & 1.21 & $\mathrm{~kg} / \mathrm{m}^{3}$ \\
\hline$a_{a}$ & 346.00 & $\mathrm{~m} / \mathrm{s}$ & 346.00 & $\mathrm{~m} / \mathrm{s}$ \\
\hline$a_{b}$ & 1500.00 & $\mathrm{~m} / \mathrm{s}$ & 1500.00 & $\mathrm{~m} / \mathrm{s}$ \\
\hline \multicolumn{5}{|l|}{ Variables } \\
\hline$A_{\text {noz }}$ & $7.85 \mathrm{E}-07$ & $\mathrm{~m}^{2}$ & 7.85E-07 & $\mathrm{m}^{2}$ \\
\hline$\rho_{b}$ & 1070.68 & $\mathrm{~kg} / \mathrm{m}^{3}$ & 1147.79 & $\mathrm{~kg} / \mathrm{m}^{3}$ \\
\hline GLR & 0.30 & & 0.30 & \\
\hline$P_{o}$ & 30.00 & $\mathrm{~b}$ & 30.00 & $\mathrm{~b}$ \\
\hline trial $N_{n o z}$ & 48.00 & & 24.00 & \\
\hline \multicolumn{5}{|c|}{ Calculations } \\
\hline$F_{b 15}$ & 0.35 & $1 / s$ & 0.16 & $1 / s$ \\
\hline$F_{b}$ & 0.44 & $1 / \mathrm{min}$ & 0.41 & $1 / \min$ \\
\hline$P_{c}$ & 15.85 & b & 15.85 & b \\
\hline$\rho_{a c}$ & 18.85 & $\mathrm{~kg} / \mathrm{m}^{3}$ & 18.85 & $\mathrm{~kg} / \mathrm{m}^{3}$ \\
\hline$F_{a}$ & 117.82 & $1 / \min$ & 117.80 & $1 / \min$ \\
\hline$F_{a e}$ & 7.53 & $1 / \min$ & 7.53 & $1 / \min$ \\
\hline$F_{\text {mix }}$ & 7.97 & $1 / \mathrm{min}$ & 7.94 & $1 / \mathrm{min}$ \\
\hline$x$ & 0.94 & & 0.95 & \\
\hline$a_{m i x}$ & 175.96 & $\mathrm{~m} / \mathrm{s}$ & 175.31 & $\mathrm{~m} / \mathrm{s}$ \\
\hline$S_{m i x}$ & 8.29 & $1 / \mathrm{min}$ & 8.26 & $1 / \min$ \\
\hline$D_{\text {coef }}$ & 0.96 & & 0.96 & \\
\hline$N_{n o z}$ & 48.00 & & 24.00 & \\
\hline$P W_{a}$ & 54.58 & & 27.28 & \\
\hline$P W_{b}$ & 1.02 & & 0.48 & \\
\hline$P W_{\text {total }}$ & 55.60 & & 27.76 & \\
\hline
\end{tabular}




\section{Conclusion}

Effervescent spray nozzle looks promising for MCB and cloud physics investigation with $\mathrm{NaCl}$ and other salt brines. A nozzle design that imparted rotational swirl to the brine as it mixed with the air was found to stabilize spray and prevent periodic slug flow. Analysis in EXCEL of particle sizers measurements from both a SMPS and an APS showed production of many nanometer sized particles that were estimated as usable for $\mathrm{MCB}$. A small number of micron sized particles were also always present but with about $90 \%$ of the sprayed mass. This is the first report with good data over this size range. A calculation model showed that brine concentration has a strong effect on total power which combined with low pressure greatly reduced power requirements. Using this model, we predict that a salt concentration of 0.2 , a nozzle area of $1 \mathrm{~mm}$ diameter, and pressure of $30 \mathrm{~b}$ would require only $28 \mathrm{kw}$ of power and 24 nozzles. Whether the model can be extended into these conditions is not certain. Using an impactor [20] [21] to filter out the large mass particles back into the brine supply combined with increased salt concentration will allow the design of an optimum system. It will also prevent problems of evaporative cooling from the large particles affecting spray rise. Upward launch of the spray to a height greater than $50 \mathrm{~m}$ with fans is quite feasible and will only increase power required by a few tens of kilowatts.

\section{Acknowledgements}

We gratefully thank Dr. Anthony Strawa, NASA AMES and Dr. Thomas Kirchstetter, LBNL for loan of a SMPS and Professor Dave Covert, University of Washington and Professor Richard Flagan, California Institute of Technology for loans of an APS. We gratefully acknowledge the space that was provided by Rick Bacon, C.E.O., Aqua Metrology Systems Limited, 1225 E. Arques Ave, Sunnyvale, CA 94085 during our initial research. We have vacated this space and now are volunteers at Parc, a Xerox Company, 3333 Coyote Hill Road, Palo Alto, CA 94304. We gratefully thank Professor Dave Covert, an expert on measuring aerosols from the Department of Atmospheric Sciences, University of Washington for helping set up the measuring system shown in Figure 8. J F thanks Alan Foster for discussions and review.

\section{Conflicts of Interest}

The authors declare no conflicts of interest regarding the publication of this paper.

\section{References}

[1] Latham, J. (1990) Control of Global Warming? Nature, 347, 339-340. https://doi.org/10.1038/347339b0

[2] Latham, J. (2002) Amelioration of Global Warming by Controlled Enhancement of the Albedo and Longevity of Low-Level Maritime Clouds. Atmospheric Science Letters, 3, 52-58. https://doi.org/10.1006/asle.2002.0048 
[3] Cooper, G., Johnston, D., Foster, J., Galbraith, L., Neukermans, A., Ormond, R., Rush, J. and Wang, Q. (2013) A Review of Some Experimental Spray Methods for Marine Cloud Brightening. International Journal of Geosciences, 4, 78-97. https://doi.org/10.4236/ijg.2013.41009

[4] Neukermans, A., Cooper, G., Foster, J., Galbraith, L., Jain, S., Latham, J. and Ormond, B. (2014) Sub-Micrometer Salt Aerosol Production Intended for Marine Cloud Brightening. Atmospheric Research, 142, 158-170.

https://doi.org/10.1016/j.atmosres.2013.10.025

[5] Neukermans, A., Cooper, G., Foster, J., Galbraith, L., Jain, S. and Ormond, B. (2013) Sub-Micrometer Salt Aerosol Production: Marine Cloud Brightening. 2013 IEEE Global Humanitarian Technology Conference (GHTC), San Jose, 20-23 October 2013, 512-515. https://doi.org/10.1109/GHTC.2013.6713739

[6] Cooper, G., Foster. J., Galbraith. L., Jain. S, Neukemans. A. and Ormond. B. (2014) Preliminary Results for Salt Aerosol Production Intended for Marine Cloud Brightening, Using Effervescent Spray Atomization. Philosophical Transactions of the Royal Society A, 372, Article ID: 20140055. https://doi.org/10.1098/rsta.2014.0055

[7] Woods, A.B. (1946) A Textbook of Sound. 2nd Edition, G. Bell and Sons Ltd., London, 51-52, 361-363.

[8] Chawla, J. (1989) The Role of Minute Droplets in the Separation of Aerosols from Gases. Chemical Engineering and Processing, 26, 201-205.

https://doi.org/10.1016/0255-2701(89)80018-2

[9] Chawla, J. (1985) Atomization of Liquids Employing the Low Sonic Velocity in Liquid/Gas Mixtures. Conference on Liquid Atomization and Spray Systems, London, 8-10 July 1985, LP/1A/5/1-7.

[10] Geoengineering May Be the Answer to Climate Change. 9.43/24.20. https://www.youtube.com/watch?v=1hhzrormtP4

[11] Sovani, S., Sojka, P. and Lefebvre, A. (2001) Effervescent Atomization. Progress in Energy and Combustion Science, 27, 483-521. https://doi.org/10.1016/S0360-1285(00)00029-0

[12] TSI Inc. (2010) Model 3936 SMPS, Scanning Mobility Particle Sizer, P/N 1933796. TSI Incorporated, Shoreview, MN.

[13] TSI Inc. (2009) Model 3080 Electrostatic Classifier. P/N 1933792, TSI Incorporated, Shoreview, MN.

[14] TSI Inc. (2002) Model 3010 CPC Condensation Particle Counter. P/N 1933010. TSI Incorporated, Shoreview, MN.

[15] TSI Inc. (2004) Model 3321 APS, Aerodynamic Particle Sizer Spectrometer, P/N 1930092. TSI Incorporated, Shoreview, MN.

[16] Lee, J.F. and Sears, F.W. (1955) Thermodynamics. Addison Wesley, Cambridge, 243-246.

[17] TSI Inc (2002) Model 4043, General Purpose Thermal Mass Flow Meter, P/N 1980339, TSI Incorporated, Shoreview, MN.

[18] Bisko, G., Maninowski, A., Russell, L.M., Buseck, P.R and Martin, S.T. (2006) Deliquescence (DRH) and Efflorescence (ERH) Relative Humidity versus Diameter for $\mathrm{NaCl}$ Particles. Aerosol Science and Technology, 40, 97-106. https://doi.org/10.1080/02786820500484396

[19] Mooney, D.A. (1953) Mechanical Engineering Thermodynamics. Prentice-Hall, New York, 386. 
[20] Boysen, D.A. and Peters, T.M. (2010) Impactor Designed to Increase Mass Output Rate of Nanoparticles from a Pneumatic Nebulizer. Journal of Aerosol Science, 41, 170-179. https://doi.org/10.1016/j.jaerosci.2009.11.001

[21] Marple, V.A. and Willike, K. (1976) Impactor Design. Atmospheric Environment, 10, 891-896. https://doi.org/10.1016/0004-6981(76)90144-X 